\title{
A Modified Constitutive Equation for Aluminum Alloy Reinforced by Silicon Carbide Particles at Elevated Temperature
}

Yajing Yang, Fuguo Li, Zhanwei Yuan, and Huijuan Qiao

(Submitted December 2, 2012; in revised form March 27, 2013; published online April 16, 2013)

\begin{abstract}
In this paper, the constitutive relationship of an aluminum alloy reinforced by silicon carbide particles is investigated using a new method of double multivariate nonlinear regression (DMNR) in which the strain, strain rate, deformation temperature, and the interaction effect among the strain, strain rate, and deformation temperature are considered. The experimental true stress-strain data were obtained by isothermal hot compression tests on a Gleeble-3500 thermo-mechanical simulator in the temperature range of 623$773 \mathrm{~K}$ and the strain rate range of $0.001-10 \mathrm{~s}^{-1}$. The experiments showed that the material-softening behavior changed with the strain rate, and it changed from dynamic recovery to dynamic recrystallization with an increase in the strain rate. A new constitutive equation has been established by the DMNR; the correlation coefficient $(R)$ and average absolute relative error (AARE) of this model are 0.98 and $7.8 \%$, respectively. To improve the accuracy of the model, separate constitutive relationships were obtained according to the softening behavior. At strain rates of $0.001,0.01,0.1$, and $1 \mathrm{~s}^{-1}$, the $R$ and AARE are 0.9865 and $6.0 \%$, respectively; at strain rates of 5 and $10 \mathrm{~s}^{-1}$, the $R$ and AARE are 0.9860 and $3.0 \%$, respectively. The DMNR gives an accurate and precise evaluation of the flow stress for the aluminum alloy reinforced by silicon carbide particles.
\end{abstract}

Keywords constitutive relationship, double multivariate nonlinear regression, hot deformation, $\mathrm{SiC}_{\mathrm{p}} / \mathrm{Al}$ composites

\section{Introduction}

Recently, particle-reinforced metal matrix composites (MMCs) have been recognized as an important class of engineering materials for their unique comprehensive mechanical, physical, and thermal properties (Ref 1-4). Among all these $\mathrm{MMCs}, \mathrm{SiC}_{\mathrm{p}} / \mathrm{Al}$ composite materials have particularly received much attention in the automotive, electrical, and aerospace industries because of their prominent advantages such as low cost and flexible manufacturing methods (Ref 510). Due to the presence of $\mathrm{SiC}$ particles, the properties of $\mathrm{SiC}_{\mathrm{p}} /$ $\mathrm{Al}$ composites at room temperature have been improved; however, the material's plastic property is reduced, and damage and fracture readily occur at room temperature. Further investigation has found that their plasticity at high temperature is excellent and the material is often used at elevated temperatures. Moreover, the hot deformation mechanism and the flow behavior of Al-based composites are quite different from those of the unreinforced monolithic alloy (Ref 11, 12). However, very limited efforts have been made to predict the

Yajing Yang, Fuguo Li, Zhanwei Yuan and Huijuan Qiao, State Key Laboratory of Solidification Processing, School of Materials Science and Engineering, Northwestern Polytechnical University, Xi'an 710072, China. Contact e-mails: yyj4429@163.com and fuguolx@nwpu.edu.cn.

elevated temperature flow behavior of $\mathrm{SiC}_{\mathrm{p}} / \mathrm{Al}$ composites. Therefore, a comprehensive study of the hot deformation behavior of $\mathrm{SiC}_{\mathrm{p}} / \mathrm{Al}$ composites is essential.

The metal plastic process (hot rolling, forging, and extrusion) depends on various parameters including the constitutive relation, the shape of the workpiece and product, the forming speed, etc. Among these parameters, the constitutive relation is one of the most important parameters that affect the solution accuracy, and it is represented in a wide range of working conditions in mathematics for the relationship between the flow behavior of materials and the strain, strain rate and the deformation temperature. Meanwhile, numerical methods such as finite element (FE) simulation have recently been successfully applied for the analysis of various metal-forming processes (Ref 13-15). A constitutive equation is used as the FE input code for simulating the response of materials in specified loading conditions (Ref 16, 17). Therefore, the accuracy of the numerical simulation largely depends on the accuracy of the deformation behavior of the material which is being represented by the constitutive equation (Ref 18).

During the dynamic deformation process, the material undergoes several metallurgical phenomena such as work hardening, dynamic recovery (DRV), and dynamic recrystallization (DRX) (Ref 19, 20). Compared with static plastic deformation which can be treated as an isothermal process, a high strain rate deformation process is quasi-adiabatic, so that the heat cannot escape and stays where it is generated. Thus, the process will raise the temperature and affect the mechanical formability because most alloys soften with increasing temperature. For the same reason, the heat generated by plastic deformation in a region of high strain also has a detrimental effect on the mechanical formability (Ref 21, 22). And, during 
Table 1 Chemical composition of matrix in $\mathrm{SiC}$ particlereinforced Al matrix composites (mass fraction/\%)

\begin{tabular}{cccccccc}
\hline $\mathbf{C u}$ & $\mathbf{M g}$ & $\mathbf{M n}$ & $\mathbf{F e}$ & $\mathbf{S i}$ & $\mathbf{Z n}$ & $\mathbf{T i}$ & $\mathbf{A l}$ \\
\hline 4.1 & 0.64 & 0.54 & 0.37 & 0.34 & 0.1 & 0.019 & $\mathrm{Bal}$ \\
\hline
\end{tabular}

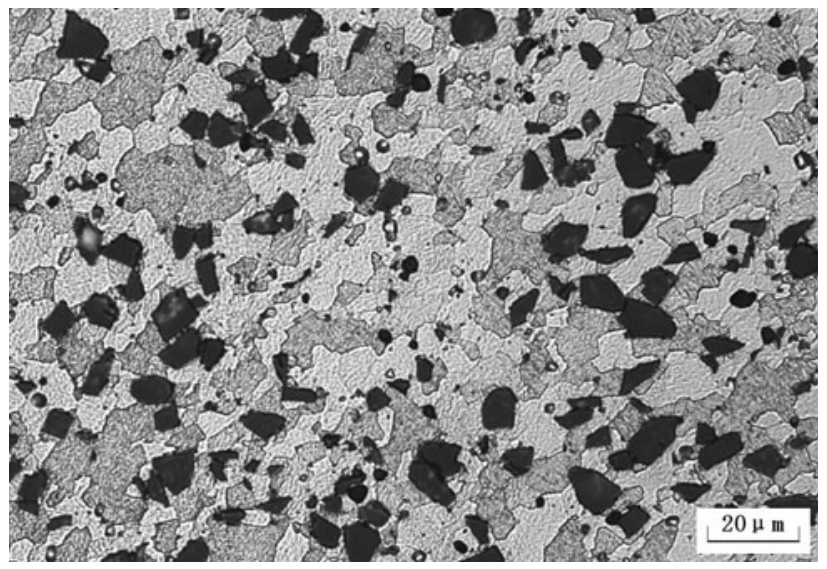

Fig. 1 The original microstructure of $\mathrm{SiCp} / \mathrm{Al}$ composites used in this study
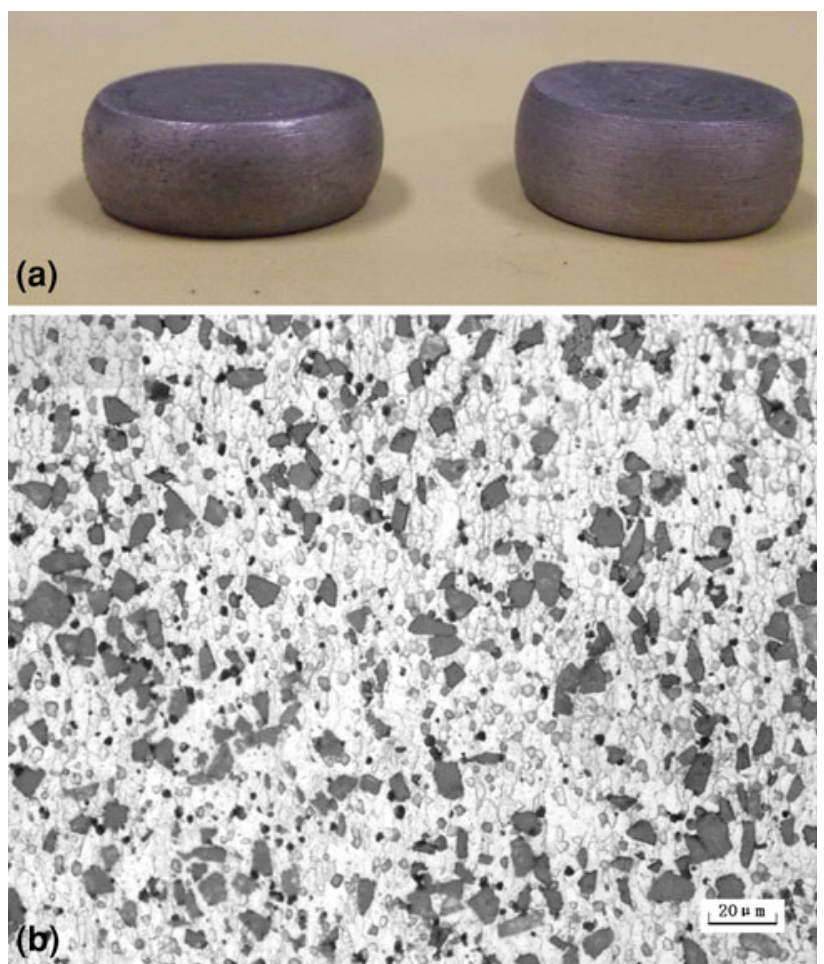

Fig. 2 (a) The specimens after experiment and (b) the microstructure after experiment

the dynamic deformation process, the heat generated in the large strain, high strain rate processing is of benefit to the process of thermal softening, such as DRV and DRX, which has significant influence on the flow stress. Therefore, an accurate description of flow stress incorporating temperature, strain, and strain rate is essential.
For the past few years, many research groups have made great efforts to develop constitutive equations of materials, and on the whole, the Johnson Cook (JC) model (Ref 23), the Zerilli-Armstrong (ZA) model (Ref 24), and Arrhenius-type constitutive equation are widely accepted. The JC model (Ref 25) has been widely used because it requires fewer material constants and needs few experiments to evaluate these constants. The JC model can only predict flow stress in a narrow domain because it is not suitable to incorporate the coupled effects of temperature and strain and the coupled effects of temperature and strain rate, and it is unsuitable to describe flow behavior in the hot working domain (Ref 25). The ZA model has been applied for different body-centered cubic materials and face-centered cubic materials at temperatures between room temperature and $0.6 T_{\mathrm{m}}\left(T_{\mathrm{m}}\right.$ is the melting point), and it is superior to the JC model when the coupled effect of temperature and strain rate (Ref 26-31) is considered. However, it is inadequate to represent the flow behavior of materials at temperatures above $0.6 T_{\mathrm{m}}$ and at lower strain rates (Ref 25). The Arrhenius-type equations could track the hot deformation behavior of materials more accurately than the others (Ref 32$)$. However, the Arrhenius-type constitutive equations also have their own drawbacks in certain conditions such as lower accuracy for evaluating the nonlinear relationship between flow stresses and process parameters at high strain rate and weak adaptability for the new experimental data (Ref 33).

The earliest general expression of the constitutive equation was advanced by Zener-Hollomon (Ref 34 ), which can be expressed as Eq 1.

$\sigma=\sigma(\varepsilon, \dot{\varepsilon}, T)$.

On the basis of an orthogonal experiment and variance analysis, Xiao et al. (Ref 35) have advanced the orthogonal experiment and variance analysis constitutive model (OVCM), and it is expressed as follows:

$\sigma=\sigma_{0} f_{\varepsilon} f_{\tilde{\varepsilon}} f_{T}$

where $\sigma_{0}$ is the initial yield stress of material under current testing conditions and $f_{\varepsilon}, f_{\dot{\varepsilon}}$, and $f_{T}$ are the influence factors of the strain, strain rate, and deformation temperature, respectively. However, the major and minor relationship of the influence factors is a relative distinction; the neglected secondary factors can simplify the analysis process in establishing the constitutive equation, but it will decrease the predicted accuracy of the constitutive equation.

Based on the OVCM and considering the coupled effects of deformation temperature and strain rate, deformation temperature and strain, the double multivariate nonlinear regression (DMNR) method is proposed. To obtain the constitutive equation of $\mathrm{SiC}_{\mathrm{p}} / \mathrm{Al}$ composites based on DMNR, hot compression tests are conducted on a Gleeble-3500 thermomechanical simulator at a wide range of temperatures (623, $673,723$, and $773 \mathrm{~K})$ and strain rates $(0.001,0.01,0.1,1,5$, and $10 \mathrm{~s}^{-1}$ ).

\section{Experimental}

\subsection{Material and Experimental Procedures}

The experimental material was an $\mathrm{Al}$ matrix composite reinforced by $15 \%$ silicon carbide particles and was prepared 

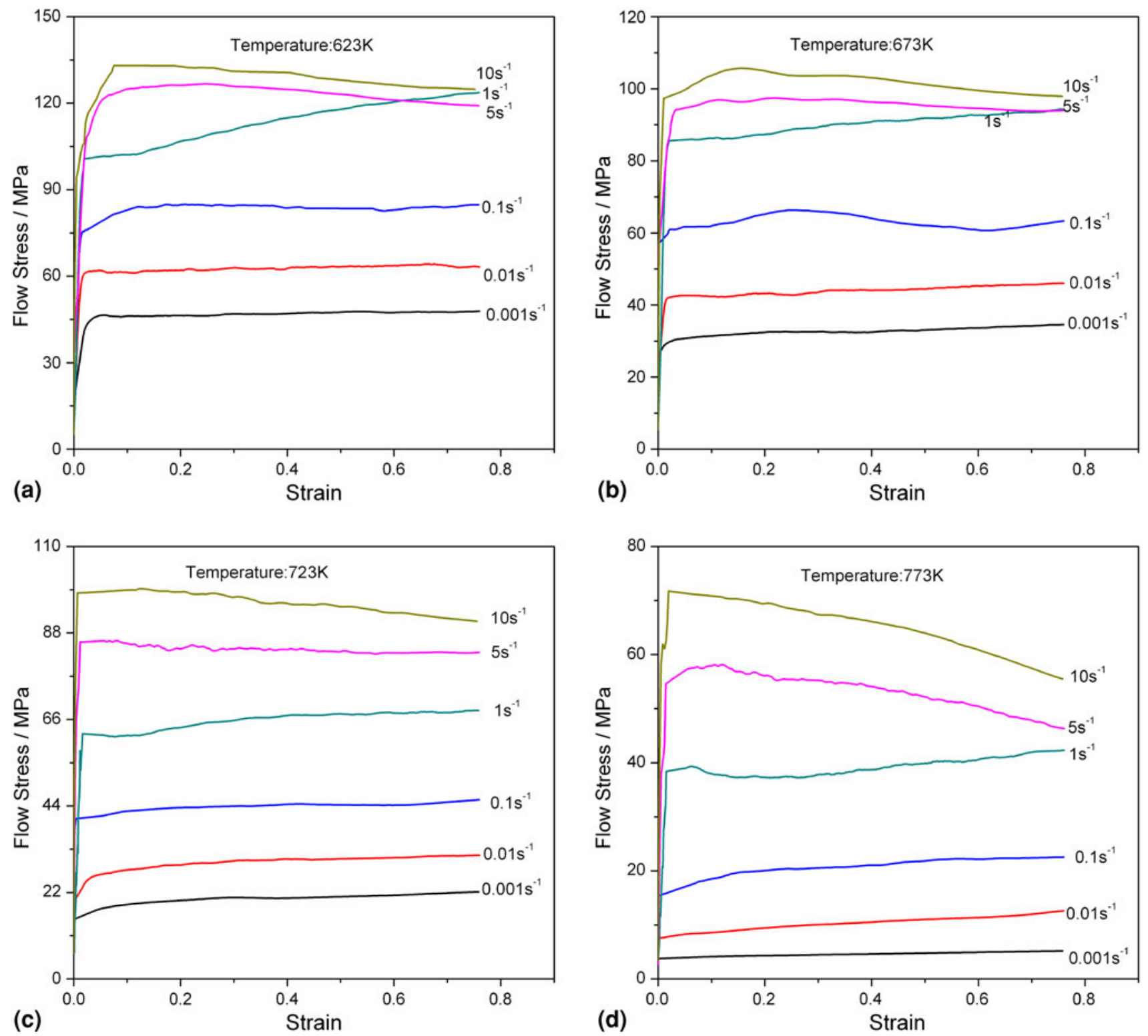

Fig. 3 Flow stress curves of $15 \% \mathrm{SiCp} / \mathrm{Al}$ composites at (a) $T=623 \mathrm{~K}$, (b) $T=673 \mathrm{~K}$, (c) $T=723 \mathrm{~K}$, and (d) $T=773 \mathrm{~K}$

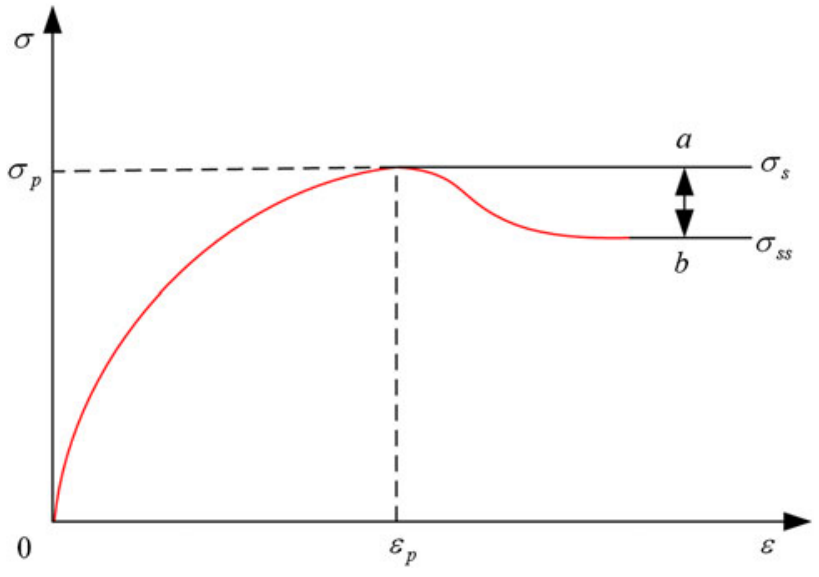

Fig. 4 The sketch map of two typical forms of flow stress-strain curves using a powder metallurgy route at Beijing Institute of Aeronautical Materials. The chemical composition of the matrix in the composites is shown in Table 1 and the alloy in the matrix is standard. Figure 1 shows the original microstructure of the material and demonstrates that the average $\mathrm{SiC}$ particle size was approximately $12 \mu \mathrm{m}$. Cylindrical specimens were $10 \mathrm{~mm}$ in diameter and $15 \mathrm{~mm}$ in height. The isothermal compression tests were carried out on a Gleeble-3500 thermal simulator. To reduce friction and to make the specimen deform uniformly during the test, both ends of the specimens were coated with graphite powder and a foil of tantalum was positioned between the surface of the specimen and the anvils. The compression temperature, which was the temperature of the specimens, ranged from 623 to $773 \mathrm{~K}$, at an interval of $50 \mathrm{~K}$, based on the real hot working temperature range of $\mathrm{SiC}_{\mathrm{p}} /$ $\mathrm{Al}$ matrix composites, and the imposed constant true strain rates were $0.001,0.01,0.1,1,5$, and $10 \mathrm{~s}^{-1}$ (Ref 11). To obtain curves of true stress-strain, the load-displacement data were 


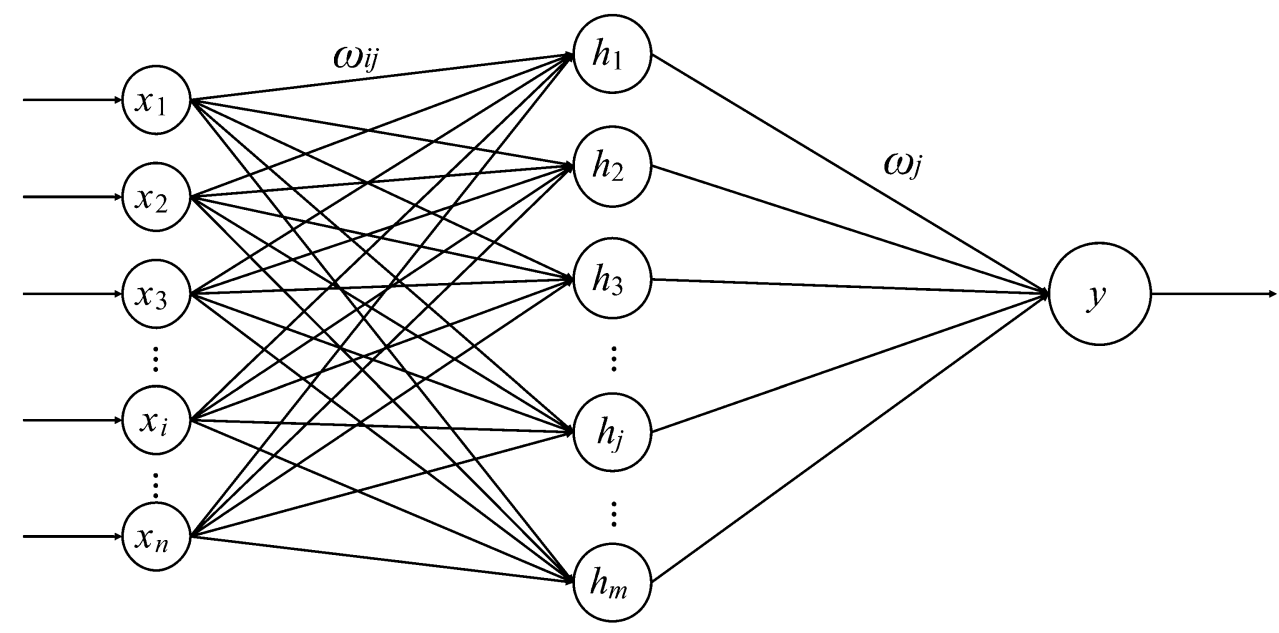
Test factors $x_{i}$
Analysis factors $h_{j}$
Objective function $y$ $(i=1,2,3 \ldots n)$ $(j=1,2,3 \ldots m)$

Fig. 5 Relationship between the flow stress and influence parameters

Table 2 Experimental program of three factors with three levels

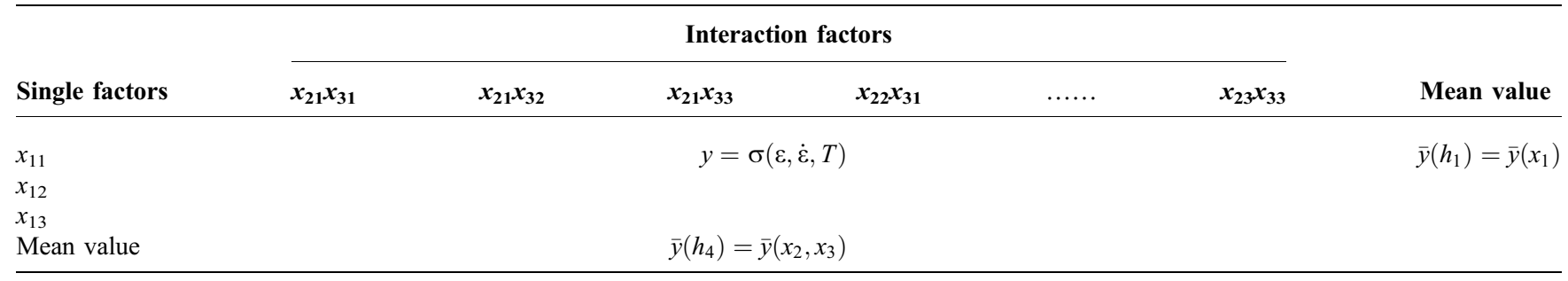

Table 3 The list of factors about $\mathrm{SiCp} / \mathrm{Al}$ composites

\begin{tabular}{|c|c|c|c|c|c|c|}
\hline \multirow[b]{2}{*}{ Level } & \multicolumn{3}{|c|}{ Single factors } & \multicolumn{3}{|c|}{ Interactive factors } \\
\hline & $\boldsymbol{f}_{\varepsilon}$ & $f_{\bar{\varepsilon}}, \mathrm{s}^{-1}$ & $f_{T}, \mathbf{K}$ & $f_{\varepsilon-\dot{\varepsilon}}, \mathbf{s}$ & $f_{\dot{\varepsilon}-T}, \mathbf{K} / \mathbf{s}$ & $f_{\varepsilon-T}, \mathbf{K}^{-1}$ \\
\hline 1 & $\varepsilon_{1}=0.04$ & 0.001 & 623 & $\varepsilon_{1}-0.001$ & $0.001-623$ & $0.04-623$ \\
\hline 2 & & & 673 & & $0.001-673$ & $0.04-673$ \\
\hline 3 & & & 723 & & $0.001-723$ & $0.04-723$ \\
\hline 4 & & & 773 & & $0.001-773$ & $0.04-773$ \\
\hline 5 & & 0.01 & 623 & $\varepsilon_{1}-0.01$ & $0.01-623$ & $0.04-623$ \\
\hline 6 & & & 673 & & $0.01-673$ & $0.04-673$ \\
\hline 7 & & & 723 & & $0.01-723$ & $0.04-723$ \\
\hline 8 & & & 773 & & $0.01-773$ & $0.04-773$ \\
\hline 9 & & 0.1 & 623 & $\varepsilon_{1}-0.1$ & $0.1-623$ & $0.04-623$ \\
\hline 10 & & & 673 & & $0.1-673$ & $0.04-673$ \\
\hline 11 & & & 723 & & $0.1-723$ & $0.04-723$ \\
\hline 12 & & & 773 & & $0.1-773$ & $0.04-773$ \\
\hline 13 & & 1 & 623 & $\varepsilon_{1}-1$ & $1-623$ & $0.04-623$ \\
\hline 14 & & & 673 & & $1-673$ & $0.04-673$ \\
\hline 15 & & & 723 & & $1-723$ & $0.04-723$ \\
\hline 16 & & & 773 & & $1-773$ & $0.04-773$ \\
\hline 17 & & 5 & 623 & $\varepsilon_{1}-5$ & $5-623$ & $0.04-623$ \\
\hline 18 & & & 673 & & $5-673$ & $0.04-673$ \\
\hline 19 & & & 723 & & $5-723$ & $0.04-723$ \\
\hline 20 & & & 773 & & $5-773$ & $0.04-773$ \\
\hline 21 & & 10 & 623 & $\varepsilon_{1}-10$ & $10-623$ & $0.04-623$ \\
\hline 22 & & & 673 & & $10-673$ & $0.04-673$ \\
\hline 23 & & & 723 & & $10-723$ & $0.04-723$ \\
\hline 24 & & & 773 & & $10-773$ & $0.04-773$ \\
\hline 456 & 0.76 & 10 & 773 & $\varepsilon_{19}-10$ & $10-773$ & $0.76-773$ \\
\hline
\end{tabular}




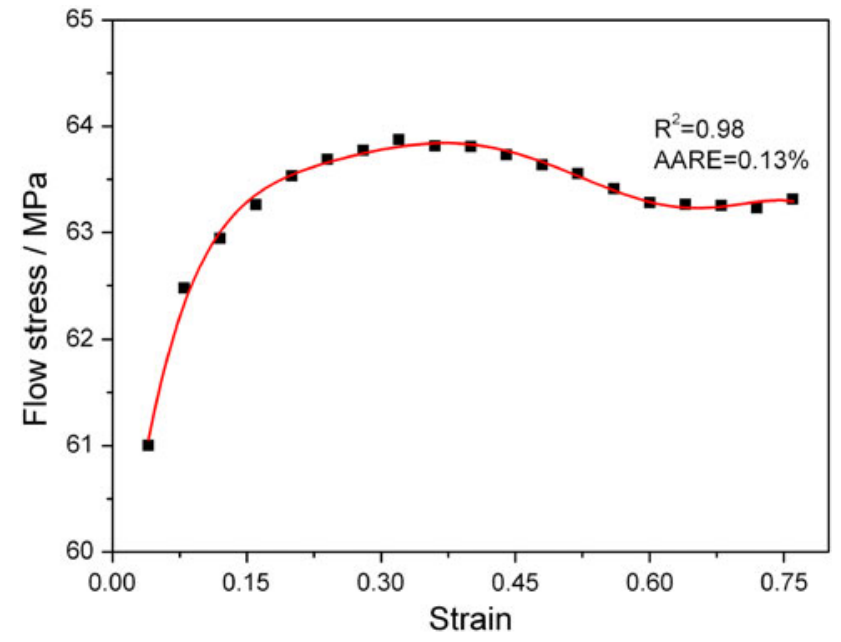

Fig. 6 The relationship between $\sigma$ and $\varepsilon$

recorded automatically. After deformation, the specimens were quenched immediately in water to preserve the hot deformed structures. The specimens after the experiment are shown in Fig. 2(a) and the microstructure after the experiment is shown in Fig. 2(b). The final deformation was approximately 53\%.

\subsection{Experimental Results}

The experimental flow stress curves of the $15 \% \quad \mathrm{SiC}_{\mathrm{p}} / \mathrm{Al}$ composites at different deformation temperatures and various strain rates are shown in Fig. 3, which reflect the influence of the deformation temperature, strain, and strain rate on the flow stress. Every curve exhibits a sharp increase at the initial stage of the stain and subsequently increases to a peak value, after which the curves display a different changing trend with the varying strain rate. At strain rates of $0.001,0.01$, and $0.1 \mathrm{~s}^{-1}$, the flow stress is in a state of steady equilibrium; at strain rates of 5 and $10 \mathrm{~s}^{-1}$, increasing the strain slightly decreases the flow stress. The flow stress at a strain rate of $1 \mathrm{~s}^{-1}$ is different from the others. Comparing Fig. 3(a), (b), (c), and (d), it is observed that the higher the deformation temperature, the lower the corresponding flow stress.

Due to different deformation mechanisms, there are two typical forms of flow stress-strain curves, and the sketch map is shown in Fig. 4. Curve $a$ is the DRV form which considers DRV to be the only softening mechanism. The flow stress will gently approach the saturation flow stress $\sigma_{\mathrm{s}}$ with the increasing of the strain; on the other hand, when DRX occurs during high temperature deformation, the shape of the flow stress-strain curve will be similar to curve $b$, which drops after the peak flow stress $\sigma_{\mathrm{p}}$ and then achieves a steady flow stress $\sigma_{\text {ss }}$ (Ref 36). Comparing Fig. 3(a), (b), (c), and (d), the softening behavior has clearly changed with the variation of the strain rate, and with the increase in the strain rate, the softening mechanism changes from DRV to DRX.

\section{Double Multivariate Nonlinear Regression (DMNR)}

As shown in Fig. 5, $x_{i}$ are the test factors, $i=1,2,3 \ldots n ; h_{j}$ are the analysis factors, $j=1,2,3 \ldots m ; y$ represents the flow
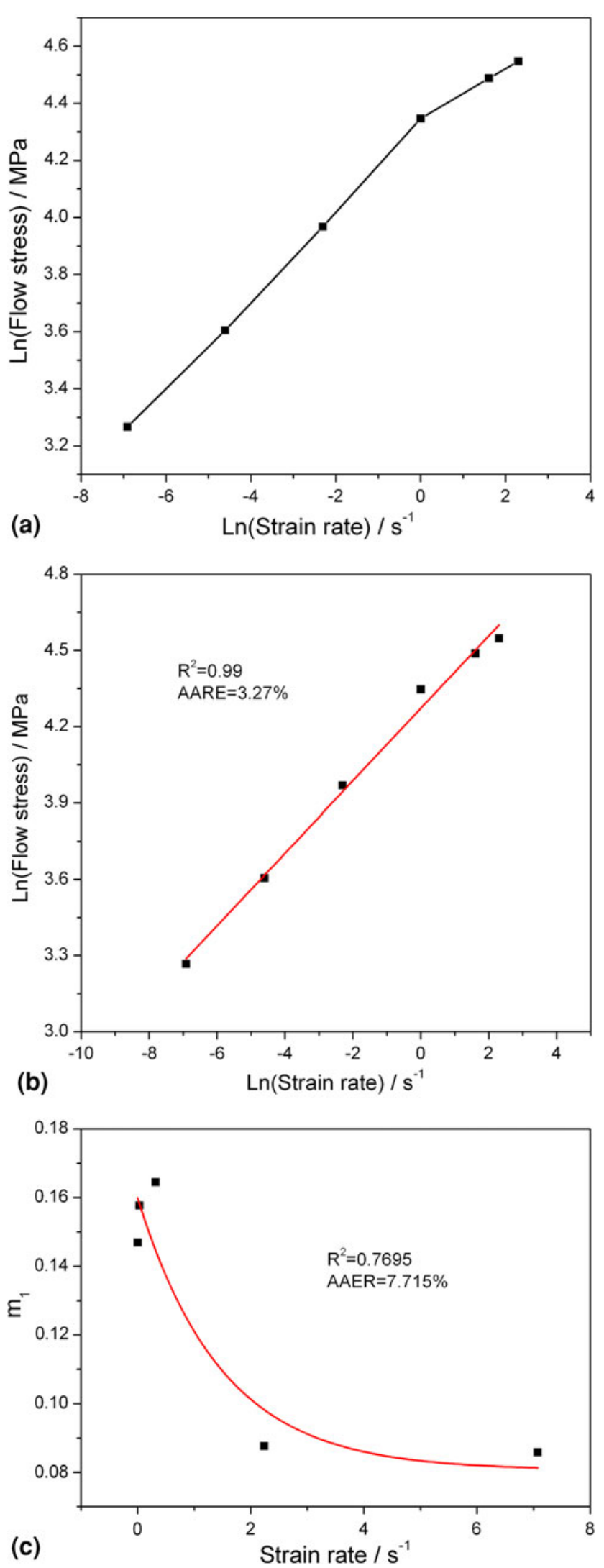

Fig. 7 (a) The relationship between $\ln \sigma$ and $\ln \dot{\varepsilon}$; (b) the linear fitting of $\ln \sigma-\ln \dot{\varepsilon}$; and (c) the relationship between the slope $m_{1}$ and $\dot{\varepsilon}$ 

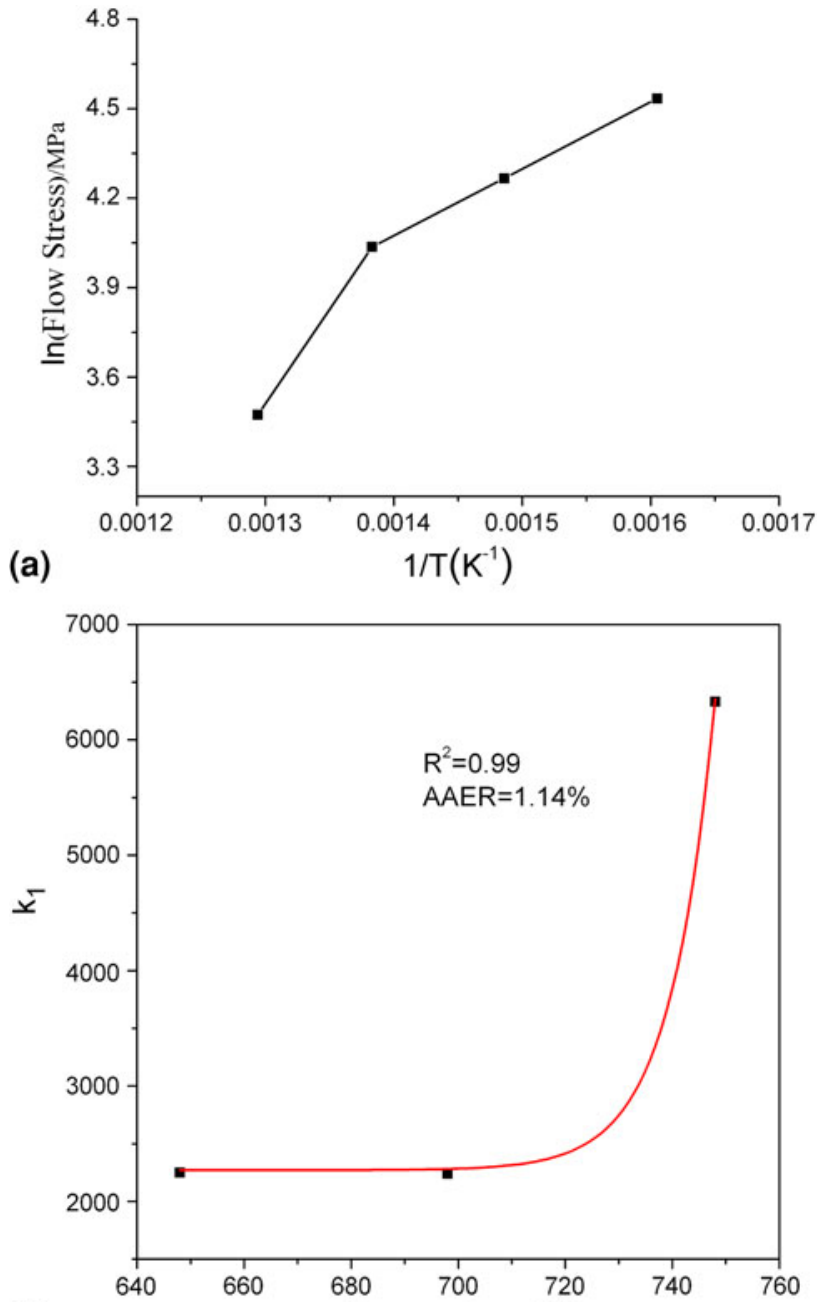

(b)

Temperature / K

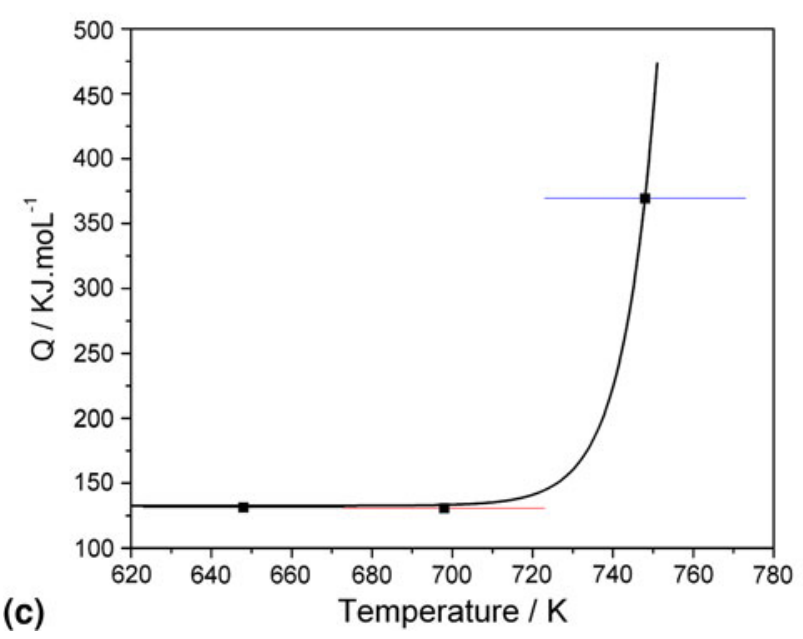

Fig. 8 (a) The relationship between $\ln \sigma$ and $1 / T$; (b) the relationship between the slope $k_{1}$ and $T$; and (c) the relationship between $Q$ and $T$

stress which is set as the objective function; the objective function $y$ is a pan-complex function of test factors $x_{\mathrm{i}}$ and analysis factors $h_{j}, y=F\left[h_{1}, h_{2}, h_{3} \ldots h_{m}\right]=f\left(x_{1}, x_{2}, x_{3} \ldots x_{n}\right)$; and $\omega_{j}$ and $\omega_{i j}$ are the converged weights.
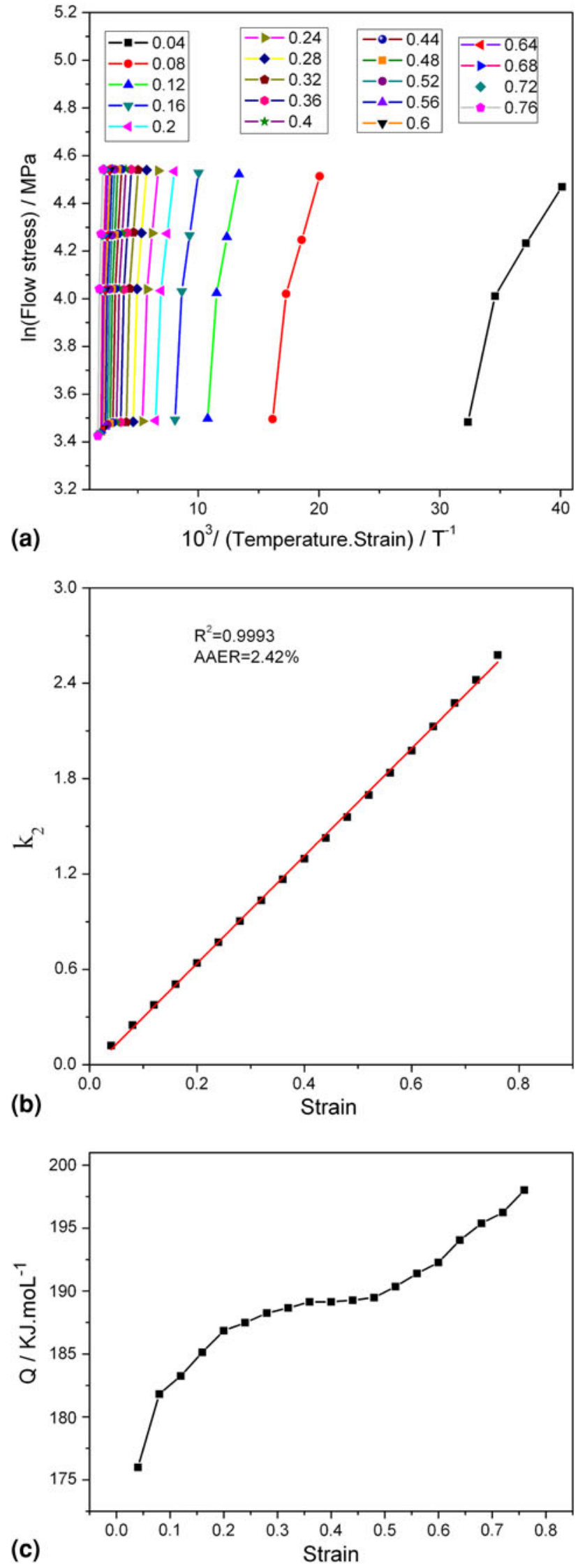

Fig. 9 (a) The relationship between $\ln \sigma$ and $10^{3} /(T \varepsilon)$; (b) the relationship between the slope $k_{2}$ and $\varepsilon$; and (c) the relationship between $Q$ and $\varepsilon$ 
Table 4 The relationship between the slope $k_{2}$ and strain

\begin{tabular}{ccccccccrrr}
\hline Strain & $\mathbf{0 . 0 4}$ & $\mathbf{0 . 0 8}$ & $\mathbf{0 . 1 2}$ & $\mathbf{0 . 1 6}$ & $\mathbf{0 . 2}$ & $\mathbf{0 . 2 4}$ & $\mathbf{0 . 2 8}$ & $\mathbf{0 . 3 2}$ & $\mathbf{0 . 3 6}$ & $\mathbf{0 . 4}$ \\
\hline Slope & 0.12061 & 0.24922 & 0.37679 & 0.50751 & 0.64031 & 0.77097 & 0.90313 & 1.0344 & 1.16662 & 1.2963 \\
\hline Strain & $\mathbf{0 . 4 4}$ & $\mathbf{0 . 4 8}$ & $\mathbf{0 . 5 2}$ & $\mathbf{0 . 5 6}$ & $\mathbf{0 . 6}$ & $\mathbf{0 . 6 4}$ & $\mathbf{0 . 6 8}$ & $\mathbf{0 . 7 2}$ & $\mathbf{0 . 7 6}$ \\
\hline Slope & 1.42692 & 1.55837 & 1.69606 & 1.83643 & 1.97671 & 2.12785 & 2.27634 & 2.42092 & 2.5785 \\
\hline
\end{tabular}

(a)
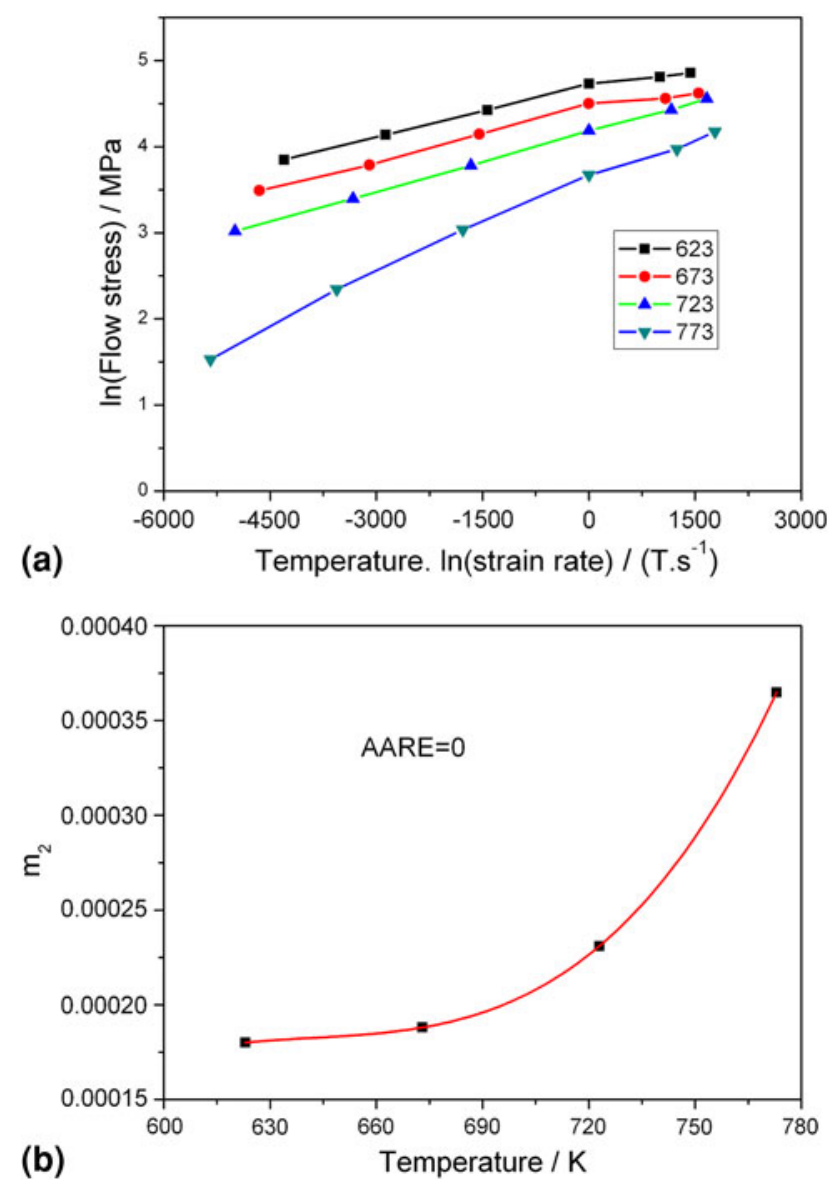

Fig. 10 (a) The relationship between $\ln \sigma$ and $T \ln \dot{\varepsilon}$ and (b) the relationship between the slope $m_{2}$ and $T$

Table 5 The relationship between the slope $m_{2}$ and temperature

\begin{tabular}{lcccc}
\hline Temperature & $\mathbf{6 2 3} \mathbf{~ K}$ & $\mathbf{6 7 3} \mathbf{~ K}$ & $\mathbf{7 2 3} \mathbf{~ K}$ & $\mathbf{7 7 3} \mathbf{~ K}$ \\
\hline Slope & $\begin{array}{r}1.79543 \\
\times 10^{-4}\end{array}$ & $\begin{array}{r}1.88163 \\
\times 10^{-4}\end{array}$ & $\begin{array}{l}2.3118 \\
\times 10^{-4}\end{array}$ & $\begin{array}{l}3.6540 \\
\times 10^{-4}\end{array}$ \\
\hline
\end{tabular}

Analysis factors $h_{j}$ are the function of test factors $x_{i}$, which are obtained by converged weights $\omega_{i j}$. The converged weights $\omega_{i j}$ represent the contribution of test factors $x_{i}$ to the analysis factors $h_{j}$, and they are determined by the interaction of test factors $x_{i}$, and they go from 0 to 1 . The objective function $y$ is obtained by the contribution functions $f\left[h_{j}\right]$, and the converged weights $\omega_{j}$ represent the contributions of functions $f\left[h_{j}\right]$ to the objective function $y$. To sum up, analysis factors $h_{j}$ are the
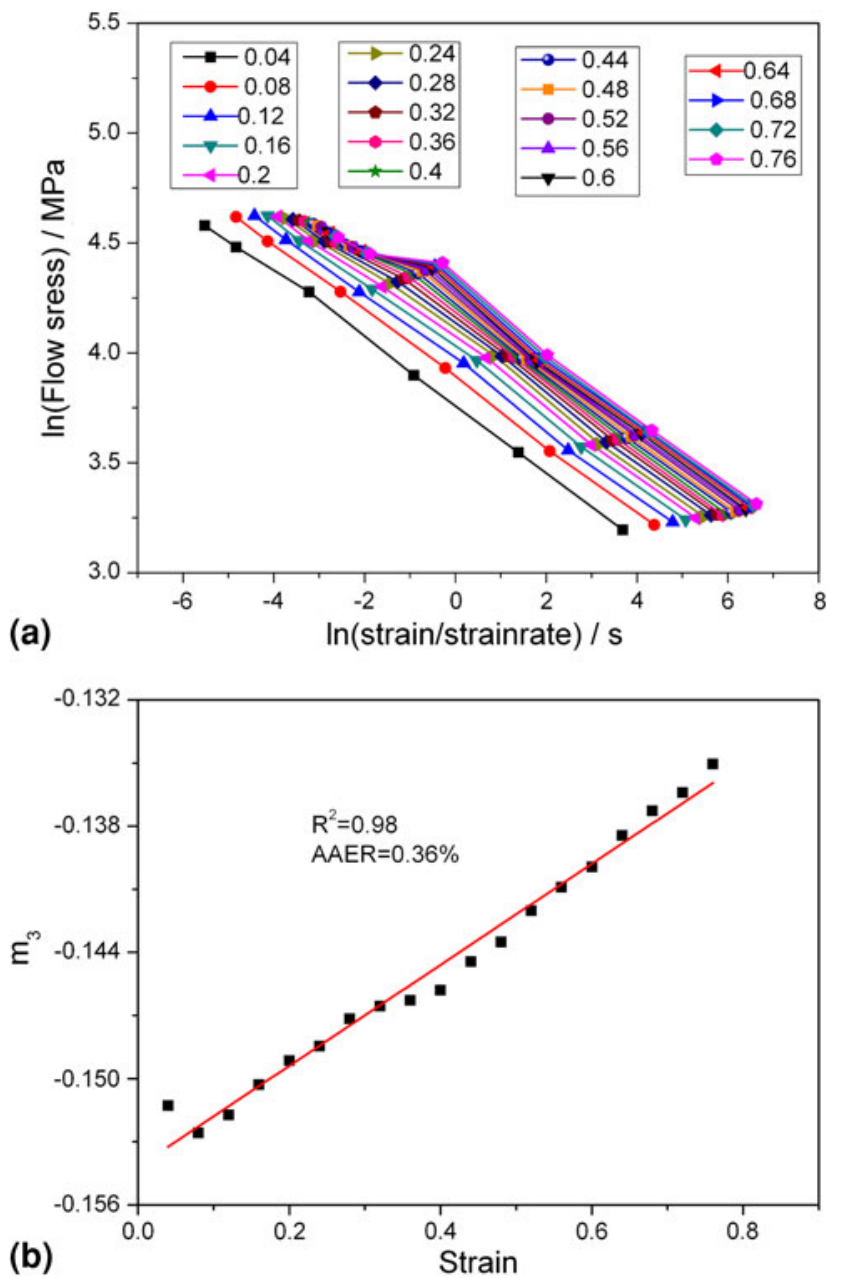

Fig. 11 (a) The relationship between $\ln \sigma$ and $\ln (\varepsilon / \dot{\varepsilon})$ at different strains and (b) the relationship between the slope $m_{3}$ and $\varepsilon$

weight functions of test factors $x_{i}$, and objective pan-complex function $y$ is the weight function of contribution functions $f\left[h_{j}\right]$, where the acquisition of the function forms of $h_{j}$ is based on the physical theory of plastic deformation (Ref 37) and the available published literatures (Ref 38-40) related to constitutive equations. The mapping relationship between the analysis factors $h_{j}$ and the objective function $y$ described as $f_{j}=f\left[h_{j}\right]$ is a contribution function, which is acquired by the nonlinear regression based on the test data scatter plot, and weights $\omega_{j}$ are acquired using the multivariate nonlinear regression based on the least-square algorithm. Therefore, the construction method for constitutive equation could be called DMNR. The so-called double nonlinear regression refers to the nonlinear regression of the contribution functions $f_{j}$ and the objective function $y$. The 
Table 6 The relationship between the slope $m_{3}$ and $\varepsilon$

\begin{tabular}{ccccccccccc}
\hline Strain & $\mathbf{0 . 0 4}$ & $\mathbf{0 . 0 8}$ & $\mathbf{0 . 1 2}$ & $\mathbf{0 . 1 6}$ & $\mathbf{0 . 2}$ & $\mathbf{0 . 2 4}$ & $\mathbf{0 . 2 8}$ & $\mathbf{0 . 3 2}$ & $\mathbf{0 . 3 6}$ & $\mathbf{0 . 4}$ \\
\hline Slope & -0.15128 & -0.15258 & -0.15173 & -0.15029 & -0.14914 & -0.14846 & -0.14716 & -0.14655 & -0.14628 & -0.1458 \\
\hline Strain & $\mathbf{0 . 4 4}$ & $\mathbf{0 . 4 8}$ & $\mathbf{0 . 5 2}$ & $\mathbf{0 . 5 6}$ & $\mathbf{0 . 6}$ & $\mathbf{0 . 6 4}$ & $\mathbf{0 . 6 8}$ & $\mathbf{0 . 7 2}$ & $\mathbf{0 . 7 6}$ \\
\hline Slope & -0.14444 & -0.14351 & -0.14201 & -0.1409 & -0.13993 & -0.13844 & -0.13727 & -0.13641 & -0.13504 \\
\hline
\end{tabular}

Table 7 The result of the MR test using SpSS

\begin{tabular}{|c|c|c|c|c|c|c|}
\hline \multirow{2}{*}{\multicolumn{2}{|c|}{ Model }} & \multicolumn{2}{|c|}{ Unstandardized coefficients } & \multirow{2}{*}{$\begin{array}{c}\text { Standardized coefficients } \\
\text { Beta }\end{array}$} & \multirow[b]{2}{*}{$t$} & \multirow[b]{2}{*}{ Sig } \\
\hline & & $\boldsymbol{B}$ & Std error & & & \\
\hline \multirow[t]{7}{*}{1} & (Constant) & 50.973 & 2.772 & & 18.392 & .000 \\
\hline & VAR00002 & -11.921 & .676 & -.152 & -17.622 & .000 \\
\hline & VAR00003 & -.304 & .054 & -.182 & -5.603 & .000 \\
\hline & VAR00004 & -.004 & .000 & -.251 & -29.949 & .000 \\
\hline & VAR00005 & .590 & .017 & .362 & 33.878 & .000 \\
\hline & VAR00006 & .950 & .020 & .738 & 46.633 & .000 \\
\hline & VAR00007 & .378 & .052 & .234 & 7.208 & .000 \\
\hline
\end{tabular}

Table 8 The value of correction coefficient and the material constants obtained by multivariate linear regression

\begin{tabular}{lcccccc}
\hline $\boldsymbol{A}$ & $\boldsymbol{a}$ & $\boldsymbol{b}$ & $\boldsymbol{c}$ & $\boldsymbol{d}$ & $\boldsymbol{e}$ & $\boldsymbol{f}$ \\
\hline $1.37 \times 10^{22}$ & -11.921 & -0.304 & -0.004 & 0.590 & 0.950 & 0.387 \\
\hline
\end{tabular}

constitutive equation $y \quad\left(y=F\left[h_{1}, h_{2}, h_{3} \ldots h_{m}\right]=f\left(x_{1}, x_{2}\right.\right.$, $\left.x_{3} \ldots x_{n}\right)$ ) is established as a pan-complex function relating to analysis factors $h_{j}$ and test factors $x_{i}$.

As for the constitutive equation for elevated temperature deformation of $\mathrm{SiC}_{\mathrm{p}} / \mathrm{Al}$ composites, if the independent factors strain $\varepsilon$, strain rate $\dot{\varepsilon}$, and deformation temperature $T$ are the test factors $x_{1}, x_{2}$, and $x_{3}$, then $h_{1}\left(x_{1}\right)=\varepsilon, h_{2}\left(x_{1}, x_{2}\right)=\varepsilon / \dot{\varepsilon}, h_{3}\left(x_{2}\right)$ $=\dot{\varepsilon}, h_{4}\left(x_{2}, x_{3}\right)=T \ln \dot{\varepsilon}, h_{5}\left(x_{3}\right)=1 / T$, and $h_{6}\left(x_{3}, x_{1}\right)=1 / T \varepsilon$ are determined as the analysis factors of strain item, time item, strain rate item, the interaction item between temperature and strain rate, temperature item, and the interaction item between strain and temperature, respectively.

After determination of all the analysis factors mentioned above, taking the mean stress value of each analysis factors, the contribution function $f_{j}$ could be obtained by the nonlinear regression based on the test data scatter plot, where $f_{1}=$ $f_{\varepsilon}\left[h_{1}\left(x_{1}\right)\right], f_{2}=f_{\varepsilon-\dot{\varepsilon}}\left[h_{2}\left(x_{1}, x_{2}\right)\right], f_{3}=f_{\dot{\varepsilon}}\left[h_{3}\left(x_{2}\right)\right], f_{4}=f_{\dot{\varepsilon}-T}\left[h_{4}\left(x_{2}\right.\right.$, $\left.\left.x_{3}\right)\right], f_{5}=f_{T}\left[h_{5}\left(x_{3}\right)\right], f_{6}=f_{\varepsilon-T}\left[h_{6}\left(x_{3}, x_{1}\right)\right]$.

The regression of the contribution function $f_{j}$ according to the test data list shown in Table 2 takes test factor $x_{1}$ and interaction item $x_{2} x_{3}$ as a sample and the assumption that there are three levels for each factor, that is to say there are nine factors in all, $x_{11}, x_{12}, x_{13}, x_{21}, x_{22}, x_{23}, x_{31}, x_{32}, x_{33}$. The mean stress value of $h_{1}\left(x_{1}\right)$ at different levels could be acquired as follows:

$\bar{y}\left(h_{1}\right)=\bar{y}\left(x_{1}\right)=\sum_{\dot{\varepsilon}-T} \sigma(\varepsilon, \dot{\varepsilon}, T) / 9$

where $\sigma\left(\varepsilon_{j}, T_{i}, \dot{\varepsilon}_{k}\right)$ is the flow stress obtained from the experiment.
The mean stress value of $h_{4}\left(x_{2}, x_{3}\right)$ at different levels could be acquired as follows:

$\bar{y}\left(h_{4}\right)=\bar{y}\left(x_{2}, x_{3}\right)=\sum_{\varepsilon} \sigma(\varepsilon, \dot{\varepsilon}, T) / 3$.

Using this method, the effects of other factors could be removed, and then $f_{\varepsilon}$ could be obtained by fitting $\sigma\left(\varepsilon_{j}, T_{i}, \dot{\varepsilon}_{k}\right)$ $-\varepsilon_{j}$. Using the same method to obtain $f_{\varepsilon}, f_{\varepsilon-\dot{\varepsilon}}, f_{\dot{\varepsilon}}, f_{\dot{\varepsilon}-T}, f_{T}$, and $f_{T-\varepsilon}$ can also be determined. After determining all of the contribution functions $f_{j}$ mentioned above, the constitutive equation based on the DMNR method could be acquired in the following process.

Based on the analysis about the relation between the analysis factors $h_{\mathrm{j}}$ and the regression function $y$, equation 2 can be modified as

$\sigma=f_{0} f_{1} f_{2} f_{3} f_{4} f_{5} f_{6}$

where

$f_{0}=\sigma_{0}, f_{1}=f_{\varepsilon}, f_{2}=f_{\varepsilon-\dot{\varepsilon}}, f_{3}=f_{\dot{\varepsilon}}, f_{4}=f_{\dot{\varepsilon}-T}, f_{5}=f_{T}, f_{6}=f_{\varepsilon-T}$.

Taking the logarithm of both sides of Eq 5 ,

$\ln \sigma=\ln f_{0}+\ln f_{1}+\ln f_{2}+\ln f_{3}+\ln f_{4}+\ln f_{5}+\ln f_{6}$

In the method of DMNR, $f_{i}$ represent the relationship of a single analysis factor and the stress $\sigma$, but establishing the integrated constitutive equation, the contributions made by $f_{i}$ are different and the contribution could be expressed as converged weights $\omega_{j}$. So, Eq 6 can be modified as 


$$
\begin{aligned}
\ln \sigma= & \ln f_{0}+w_{1} \ln f_{1}+w_{2} \ln f_{2}+w_{3} \ln f_{3}+w_{4} \ln f_{4} \\
& +w_{5} \ln f_{5}+w_{6} \ln f_{6} .
\end{aligned}
$$

Based on multivariate nonlinear regression, the regression weight $\omega_{j}$ and $f_{0}$ mentioned in the above constitutive equation can be obtained. The established general DMNR equation is expressed as

$\sigma=f_{0} f_{1}^{w_{1}} f_{2}^{w_{2}} f_{3}^{w_{3}} f_{4}^{w_{4}} f_{5}^{w_{5}} f_{6}^{w_{6}}=f_{0} \prod_{j=1}^{m} f_{j}^{w_{j}}$.

As for the $\mathrm{SiCp} / \mathrm{Al}$ composite alloy, the constitutive equation can be expressed as

$\sigma=A\left(f_{\varepsilon}\right)^{a}\left(f_{\dot{\varepsilon}}\right)^{b}\left(f_{T}\right)^{c}\left(f_{\varepsilon-T}\right)^{d}\left(f_{\dot{\varepsilon}-T}\right)^{e}\left(f_{\varepsilon-\dot{\varepsilon}}\right)^{f}$

where $A, a, b, c, d, e$, and $f$ are material constants relating to the initial yield stress and converged weights under the experimental condition.
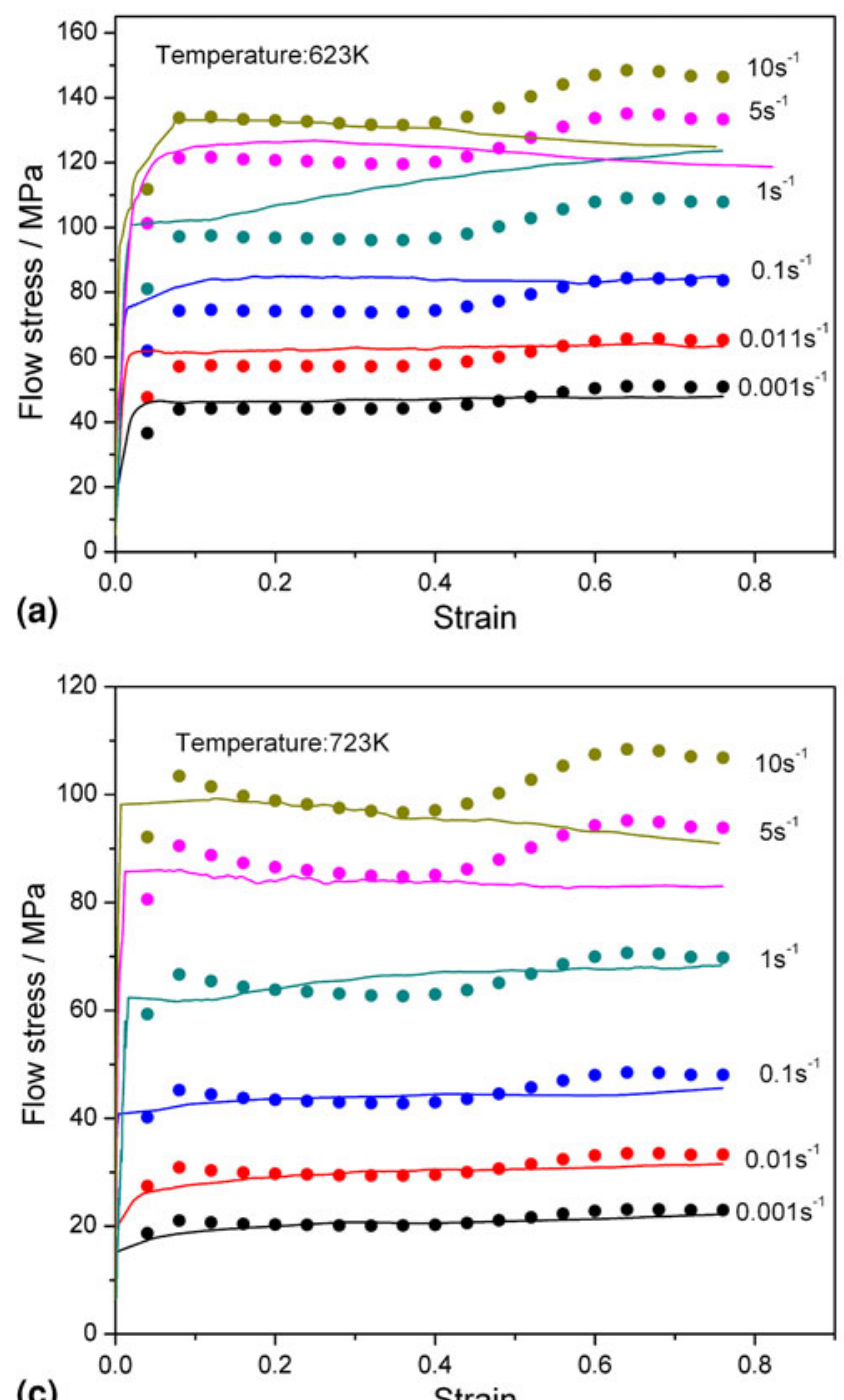

(c)

Strain
The $\mathrm{SiC}_{\mathrm{p}} / \mathrm{Al}$ composites' classification of the test factors and analysis factors according to independent factors, interactive factors, and levels is shown in Table 3.

\section{Determination of $\mathrm{SiC}_{\mathrm{p}} / \mathrm{Al}$ Composites' Constitutive Equation}

\subsection{Determination of the Contribution Functions $f_{i}$}

Taking the average flow stress under different strains, a scatter plot of $\sigma-\varepsilon$, as shown in Fig. 6, could be obtained, and a sixth-order polynomial function is employed to fit the variation trend of the scatter plot with a good correlation and generalization. The sixth-order polynomial function of $\sigma-\varepsilon$ is

$$
\begin{aligned}
\sigma= & -1213.310 \varepsilon^{6}+3187.366 \varepsilon^{5}-3283.930 \varepsilon^{4}+1702.518 \varepsilon^{3} \\
& -480.018 \varepsilon^{2}+73.182 \varepsilon+58.798 .
\end{aligned}
$$

(b)
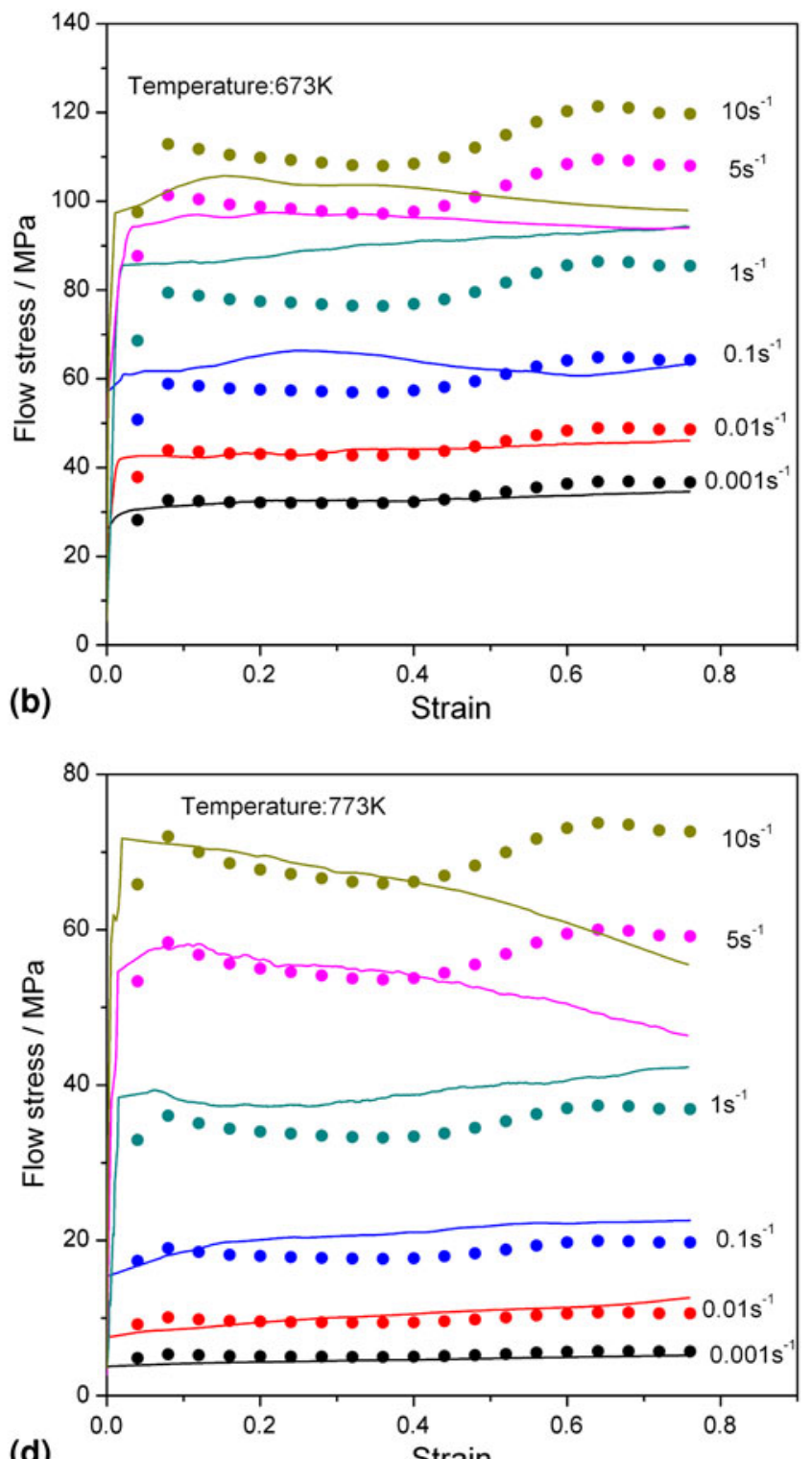

(d)

Fig. 12 The comparison of the experimental data and the predicted data at (a) $T=623 \mathrm{~K}$, (b) $T=673 \mathrm{~K}$, (c) $T=723 \mathrm{~K}$, and (d) $T=773 \mathrm{~K}$. The line represents the experimental data; the scatter plot represents the predicted data 
The contribution function $f_{\varepsilon}$ of the independent factor $\varepsilon$ can be described as

$$
\begin{aligned}
f_{\varepsilon}= & -1213.310 \varepsilon^{6}+3187.366 \varepsilon^{5}-3283.930 \varepsilon^{4}+1702.518 \varepsilon^{3} \\
& -480.018 \varepsilon^{2}+73.182 \varepsilon+58.798 .
\end{aligned}
$$

Taking the average flow stress under different strain rates, the scatter plot of $\ln \sigma-\ln \dot{\varepsilon}$ could be obtained, as shown in Fig. 7(a). By using linear regression for the data points, the relationship of $\ln \sigma-\ln \dot{\varepsilon}$ is shown in Fig. 7(b), and the linear slope is 0.14246 . In Fig. 7(a), the slope has changed sharply at a strain rate of $1 \mathrm{~s}^{-1}$. To obtain a fitted curve reacting to the objective law of the experimental data, the slope $m_{1}$ is expressed as a function of $\dot{\varepsilon}$ which is shown in Fig. 7(c), and the relation between them is expressed as follows:

$m_{1}=0.07941 \exp (-\dot{\varepsilon} / 1.48331)+0.08064$.

Taking the exponentiation of both $\ln \sigma$ and $\ln \dot{\varepsilon}$ and neglecting the constant coefficient, the contribution function $f_{\dot{\varepsilon}}$ of the independent factor $\dot{\varepsilon}$ is obtained. So, $f_{\dot{\varepsilon}}$ could be expressed as

$f_{\dot{\varepsilon}}=(\dot{\varepsilon})^{0.07941 \exp (-\dot{\varepsilon} / 1.48331)+0.08064}$.

Taking the average flow stress under different temperatures, the scatter plot of $\ln \sigma-T$, as shown in Fig. 8(a), could be obtained. In Fig. 8(a), the same law with the prior is noticed.

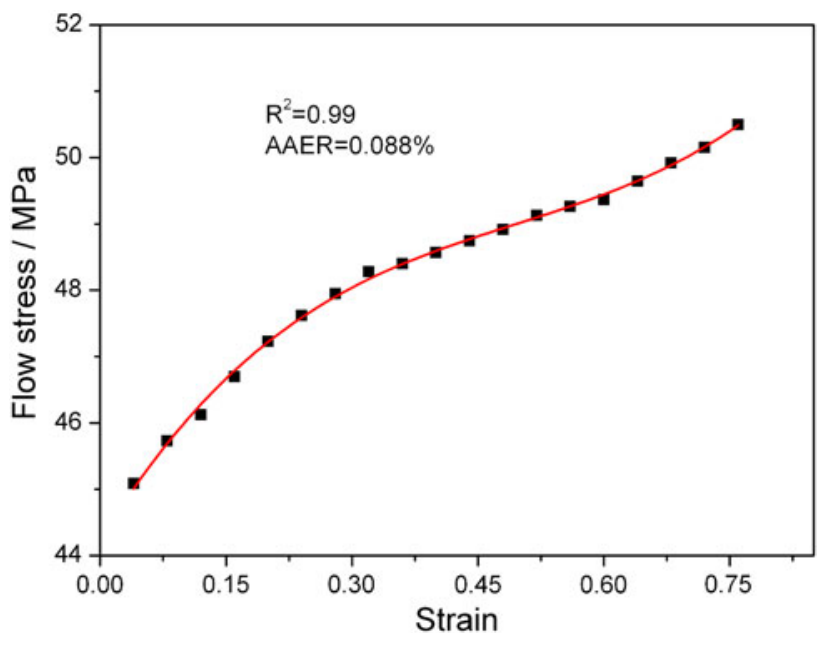

Fig. 13 The relationship between $\sigma$ and $\varepsilon$
Then, the relationship between the slope $k_{1}$ and temperature $T$ is shown in Fig. 8(b), and $k_{1}$ is expressed as

$k_{1}=6.14 \times 10^{-36} \exp (T / 8.36765)+2270.776$.

Taking into account the exponentiation of both $\ln \sigma$ and $k_{1} / T$, the contribution function $f_{T}$ of the independent factor $T$ could be described as

$f_{T}=\exp \left(\frac{6.14 \times 10^{-36} \exp (\mathrm{T} / 8.36765)+2270.776}{T}\right)$

And, Eq 15 could be modified as

$f_{T}=\exp \left(\frac{5.1048 \times 10^{-35} \exp (T / 8.36765)+18829.23166}{R T}\right)$

where $R$ is the universal gas constant $(8.314 \mathrm{~J} / \mathrm{mol} \mathrm{K})$, and the apparent activation energy $Q$ calculated by the following equation:

$Q=\frac{1}{m}\left(5.1048 \times 10^{-35} \exp (T / 8.36765)+18829.23166\right)$

where $\mathrm{m}$ is the slope of the Fig. 7(b) and $m=0.14246$. So, Eq 17 could be modified as

$Q=3.583 \times 10^{-34} \exp \left(\frac{T}{8.36765}\right)+132172.060$.

Figure 8(c) shows the curves of the apparent activation energy $Q$ and the deformation temperature $T$ based on Eq 18 .

The relationship between the flow stress and the interaction effect between strain and deformation temperature is illustrated in Fig. 9(a). The fitted linear slopes $k_{2}$ at different strains are given in Table 4, and the scatter plot of $k_{2}$ under different strains is shown in Fig. 9(b), using linear regression for the scatters. The expression for the slope $k_{2}$ is

$k_{2}=3.38353 \varepsilon-0.03952$.

Then, the contribution function $f_{\varepsilon-T}$ of the interaction factor $\varepsilon-T$ can be described as

$f_{\mathrm{T}-\varepsilon}=\exp \left(\frac{1000 k_{2}}{T \varepsilon}\right)$

Taking $k_{2}$ into Eq 20, $f_{T-\varepsilon}$ could expressed as

\begin{tabular}{|c|c|c|c|c|c|}
\hline \multirow[b]{2}{*}{ Mode } & & \multicolumn{2}{|c|}{ Unstandardized coefficients } & \multirow{2}{*}{$\begin{array}{c}\text { Standardized coefficients } \\
\text { Beta }\end{array}$} & \multirow[b]{2}{*}{ Sig } \\
\hline & & $\boldsymbol{B}$ & Std error & & \\
\hline \multirow[t]{7}{*}{1} & (Constant) & -21.777 & 2.471 & & .000 \\
\hline & VAR00002 & 5.948 & .624 & .229 & .000 \\
\hline & VAR00003 & -2.631 & .179 & -1.342 & .000 \\
\hline & VAR00004 & -.004 & .000 & -.204 & .000 \\
\hline & VAR00005 & .569 & .019 & .343 & .000 \\
\hline & VAR00006 & 1.125 & .027 & .731 & .000 \\
\hline & VAR00007 & 2.889 & .200 & 1.381 & .000 \\
\hline
\end{tabular}

Table 9 The result of the MR test using SpSS 


$$
\begin{aligned}
f_{T-\varepsilon} & =\exp \left(\frac{1000(3.38353 \varepsilon-0.03952)}{T \varepsilon}\right) \\
& =\exp \left(\frac{1}{R T} \frac{(28130.668-328.569)}{\varepsilon}\right)
\end{aligned}
$$

where $R$ is the universal gas constant $(8.314 \mathrm{~J} / \mathrm{mol} \mathrm{K})$, and $Q$ could be calculated by the following equation:

Table 10 The value of correction coefficient and the material constants obtained by multivariate linear regression

\begin{tabular}{lcccccc}
\hline $\boldsymbol{A}$ & $\boldsymbol{a}$ & $\boldsymbol{b}$ & $\boldsymbol{c}$ & $\boldsymbol{d}$ & $\boldsymbol{e}$ & $\boldsymbol{f}$ \\
\hline $3.49 \times 10^{-10}$ & 5.948 & -2.631 & -0.004 & 0.569 & 1.125 & 2.889 \\
\hline
\end{tabular}
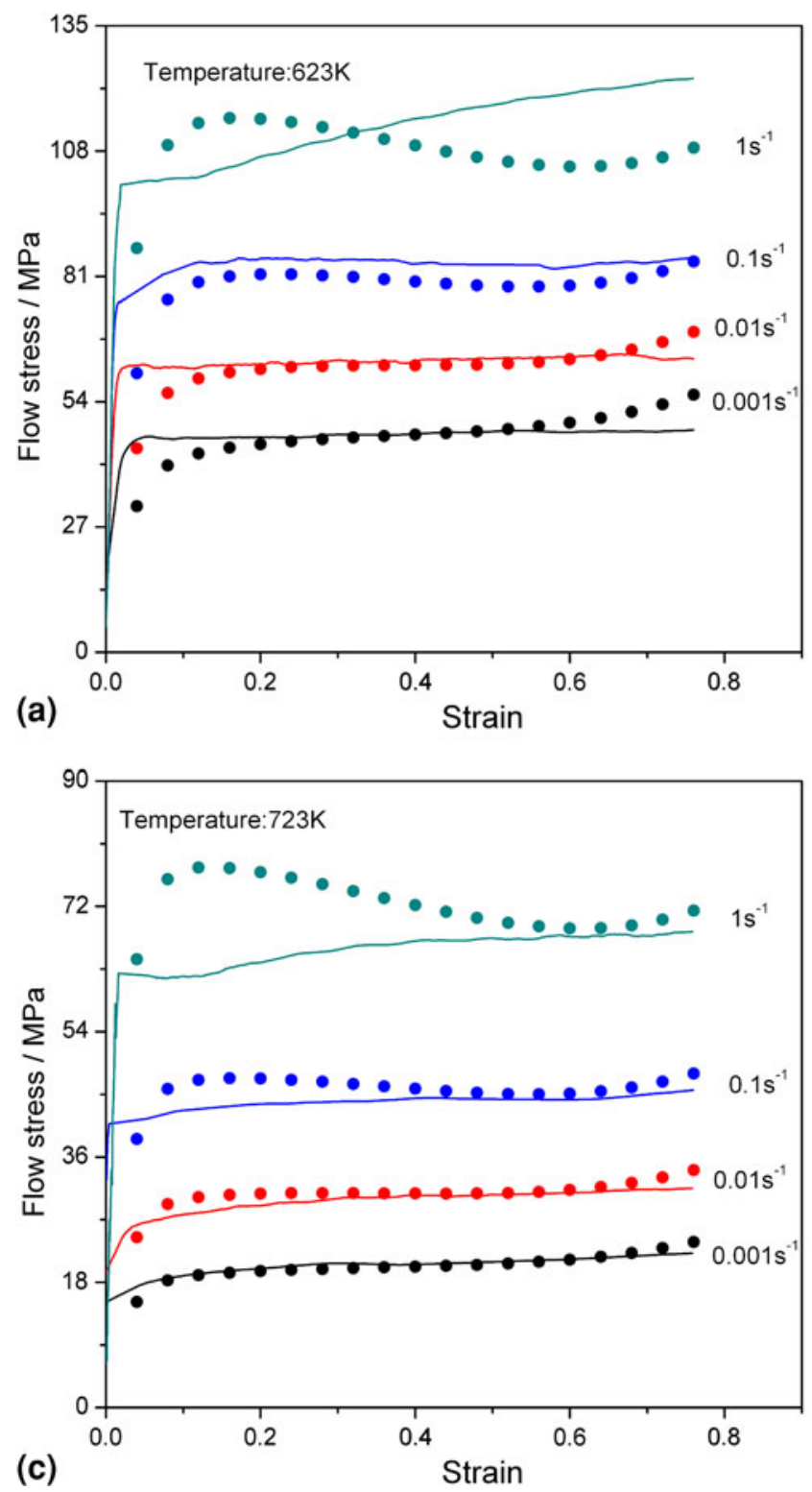

$Q=\frac{1}{m}(28130.668-328.569 / \varepsilon)$.

Taking the parameter $m=0.14246$ into Eq 20, $Q$ could be expressed as follows:

$Q=197463.6278-2306.396743 / \varepsilon$

Taking each slope in the table into Eq 20, the scatter plot of $Q-\varepsilon$ is shown in Fig. 8(c).

The relationship between the flow stress and the interaction effect between the strain rate and deformation temperature is illustrated in Fig. 10(a). The fitted linear slopes $m_{2}$ at different temperatures are given in Table 5, and the scatter plot of $m_{2}$ at different temperatures is shown in Fig. 10(b). Using nonlinear regression for the scatters, the expression for the slope $m_{2}$ is
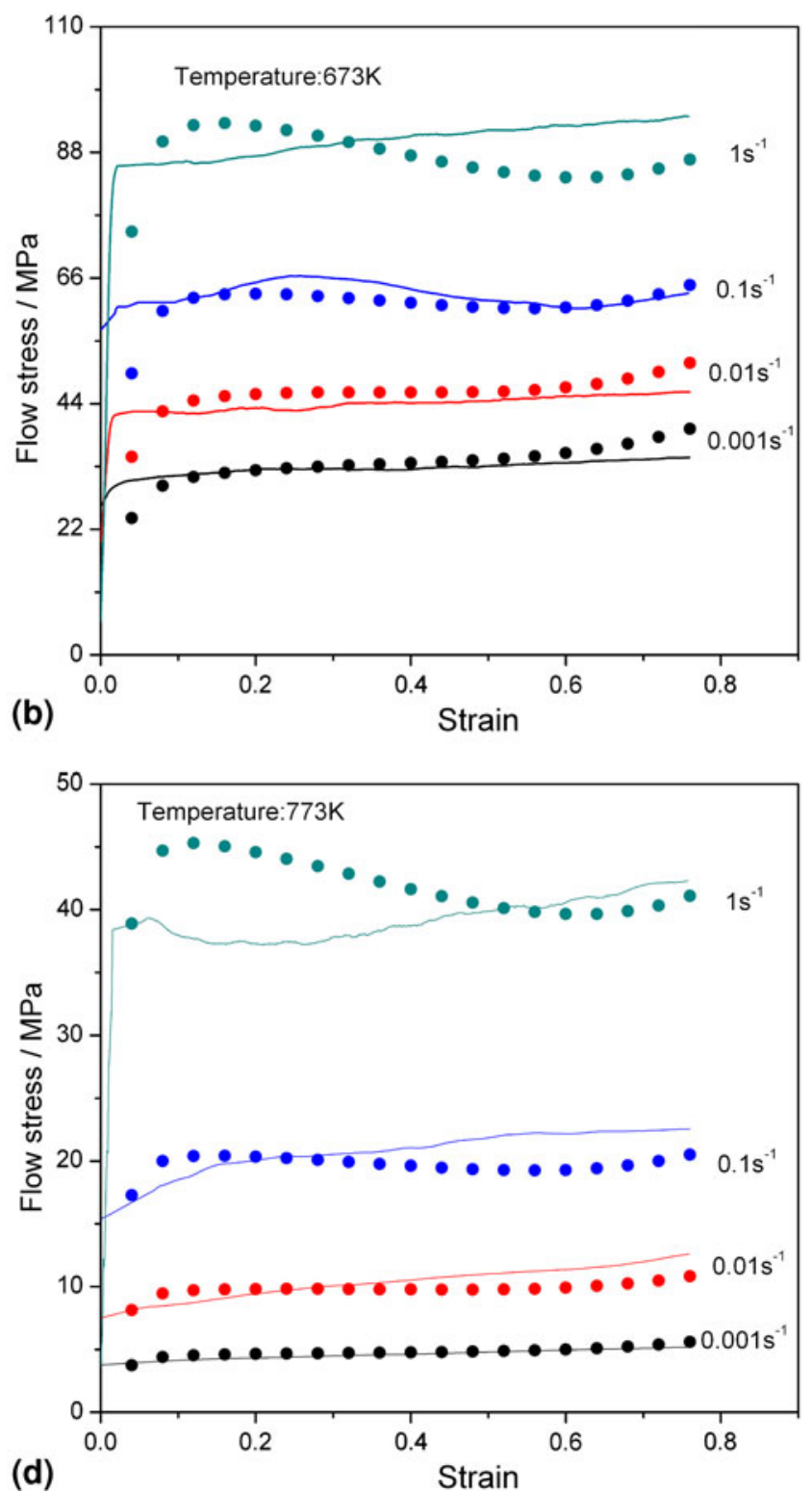

(d)

Fig. 14 The comparison of the experimental data and the predicted data at (a) $T=623 \mathrm{~K}$, (b) $T=673 \mathrm{~K}$, (c) $T=723 \mathrm{~K}$, and (d) $T=773 \mathrm{~K}$. The line represents the experimental data; the scatter plot represents the predicted data 


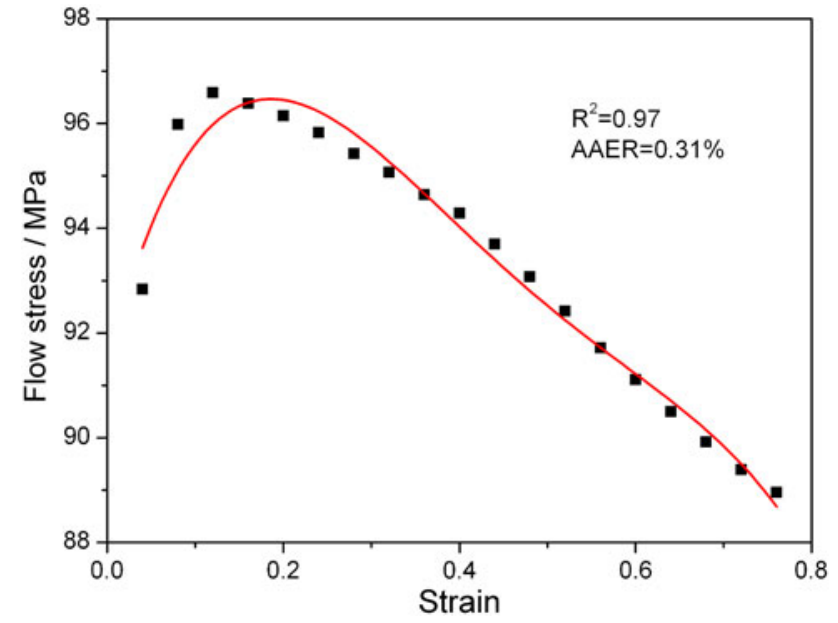

Fig. 15 The relationship between $\sigma$ and $\varepsilon$

Table 11 The result of the MR test using SpSS

\begin{tabular}{lrrrrr}
\hline & & \multicolumn{2}{c}{$\begin{array}{c}\text { Unstandardized } \\
\text { coefficients }\end{array}$} & Standardized coefficients \\
Model & B & & Std error & $\begin{array}{c}\text { Beta } \\
\text { Sig }\end{array}$ \\
\cline { 2 - 4 } 1 (Constant) & 14.120 & 1.037 & & .000 \\
VAR00002 & -2.834 & .243 & -.259 & .000 \\
VAR00003 & -3.850 & .448 & -.348 & .000 \\
VAR00004 & -.005 & .000 & -.725 & .000 \\
VAR00005 & .607 & .023 & 1.035 & .000 \\
VAR00006 & 1.023 & .132 & .519 & .000 \\
VAR00007 & 1.871 & .080 & .921 & .000 \\
\hline
\end{tabular}

Table 12 The value of correction coefficient and the material constants obtained by multivariate linear regression

\begin{tabular}{lcccccc}
\hline $\boldsymbol{A}$ & $\boldsymbol{a}$ & $\boldsymbol{b}$ & $\boldsymbol{c}$ & $\boldsymbol{d}$ & $\boldsymbol{e}$ & $\boldsymbol{f}$ \\
\hline 1355932.544 & -2.834 & -3.850 & -0.005 & 0.607 & 1.023 & 1.871 \\
\hline
\end{tabular}

$$
\begin{aligned}
m_{2}= & -0.01962+9.23574 \times 10^{-5} T-1.43752 \times 10^{-7} T^{2} \\
& +7.46667 \times 10^{-11} T^{3}
\end{aligned}
$$

Then, the contribution function $f_{T-\dot{\varepsilon}}$ of the interaction factor $T-\dot{\varepsilon}$ can be described as

$f_{T-\dot{\varepsilon}}=(\dot{\varepsilon})^{T\left(-0.01962+9.23574 \times 10^{-5} T-1.43752 \times 10^{-7} T^{2}+7.46667 \times 10^{-11} T^{3}\right)}$.

The relationship between the flow stress and the interaction effect between strain and strain rate is illustrated in Fig. 11(a). The fitted linear slopes of $\ln \sigma$ and $\ln \varepsilon / \dot{\varepsilon}$ under different strains are shown in Table 6 , and the scatter plot of $m_{3}$ at different strains is shown in Fig. 11(b). Using linear regression for the scatters, the relation between the slope $m_{3}$ and strain could be expressed as

$m_{3}=0.02401 \varepsilon-0.1542$

Then, the contribution function $f_{\varepsilon-\dot{\varepsilon}}$ of the interaction factor $\varepsilon-\dot{\varepsilon}$ could be described as $f_{\varepsilon-\dot{\varepsilon}}=(\varepsilon / \dot{\varepsilon})^{0.02401 \varepsilon-0.1542}$.

$f_{\varepsilon-\dot{\varepsilon}}$ is the function of $\varepsilon / \dot{\varepsilon}$, the physical meaning of which is time, so $f_{\varepsilon-\dot{\varepsilon}}$ is the time term and it indicates the effect of time on the flow stress.

\subsection{Determination of the Converged Weights $\omega_{j}$}

Taking the logarithm of both sides of Eq 10,

$$
\begin{aligned}
\ln \sigma= & \ln A+a \ln f_{\varepsilon}+b \ln f_{\dot{\varepsilon}}+c \ln f_{T}+d \ln f_{\varepsilon-T} \\
& +e \ln f_{\dot{\varepsilon}-T}+f \ln f_{\varepsilon-\dot{\varepsilon}} .
\end{aligned}
$$

The present study explores least-squares regression with the independent variables $\ln f_{\varepsilon}, \ln f_{\dot{\varepsilon}}, \ln f_{T}, \ln f_{\varepsilon-T}, \ln f_{\dot{\varepsilon}-T}, \ln f_{\varepsilon-\dot{\varepsilon}}$ and the dependent variable $\ln \sigma$ obtained in this test, as multivariate regression (MR) analysis is a highly flexible system for examining the relationship of a collection of independent variables to an independent dependent variable.

Through the MR test using the SpSS software, the converged weights could be determined easily, and the result is shown in Table 7. In the table, B is the correction coefficient; VAR00001 stands for $\ln \sigma$ ( $\sigma$ is the experimental data), VAR00002 is $\ln \left(f_{\varepsilon}\right)$, VAR00003 is $\ln \left(f_{\dot{\varepsilon}}\right)$, VAR00004 is $\ln \left(f_{T}\right)$, VAR00005 is $\ln \left(f_{\varepsilon-T}\right)$, VAR00006 is $\ln \left(f_{\dot{\varepsilon}-T}\right)$, and VAR00007 is $\ln \left(f_{\varepsilon-\dot{\varepsilon}}\right)$. It is shown that the linear correlation is quite excellent. Then, the correction coefficient $A$ and the contribution weight $a, b, c, d, e$, and $f$, as shown in Table 8 , could be obtained. Taking the parameters of $A, a, b, c, d, e$, and $f$ into Eq 10, the constitutive equation of $\mathrm{SiC}_{\mathrm{p}} / \mathrm{Al}$ composites at elevated temperature could be obtained.

\subsection{Verification of Constitutive Model}

The predicted flow stress from the modified constitutive equation based on DMNR for elevated temperature flow behavior of the aluminum alloy reinforced by 15 vol.\% silicon carbide particles is shown in Fig. 12. The predictability of the model is quantified in terms of the correlation coefficient $(R)$ and average absolute relative error (AARE). $R$ is a commonly employed statistical parameter and provides information on the strength of the linear relationship between the experimental and predicted data. However, a higher value of $R$ may not necessarily imply better performance of the model because of the tendency of the equation to be partial to higher or lower values. The AARE is calculated via a term-by-term comparison of the relative error in the prediction to the actual value of the variable. Thus, the AARE is an unbiased statistic for measuring the predictive capability of a model. And, it is obvious from its definition that the smaller the AARE values, the better the model performance and vice versa (Ref 41$)$. These values are calculated as follows:

$$
\begin{aligned}
& R=\frac{\sum_{i=1}^{N}\left(E_{i}-\bar{E}\right)\left(P_{i}-\bar{P}\right)}{\sqrt{\sum_{i=1}^{N}\left(E_{i}-\bar{E}\right)^{2} \sum_{i=1}^{N}\left(P_{i}-\bar{P}\right)^{2}}} \\
& \operatorname{AARE}(\%)=\frac{1}{N} \sum_{i=1}^{i=N}\left|\frac{E_{i}-P_{i}}{E_{i}}\right| \times 100
\end{aligned}
$$

where $E$ is the experimental data and $P$ is the predicted value. $\bar{E}$ and $\bar{P}$ are the mean values of $E$ and $P$, respectively. $N$ is 

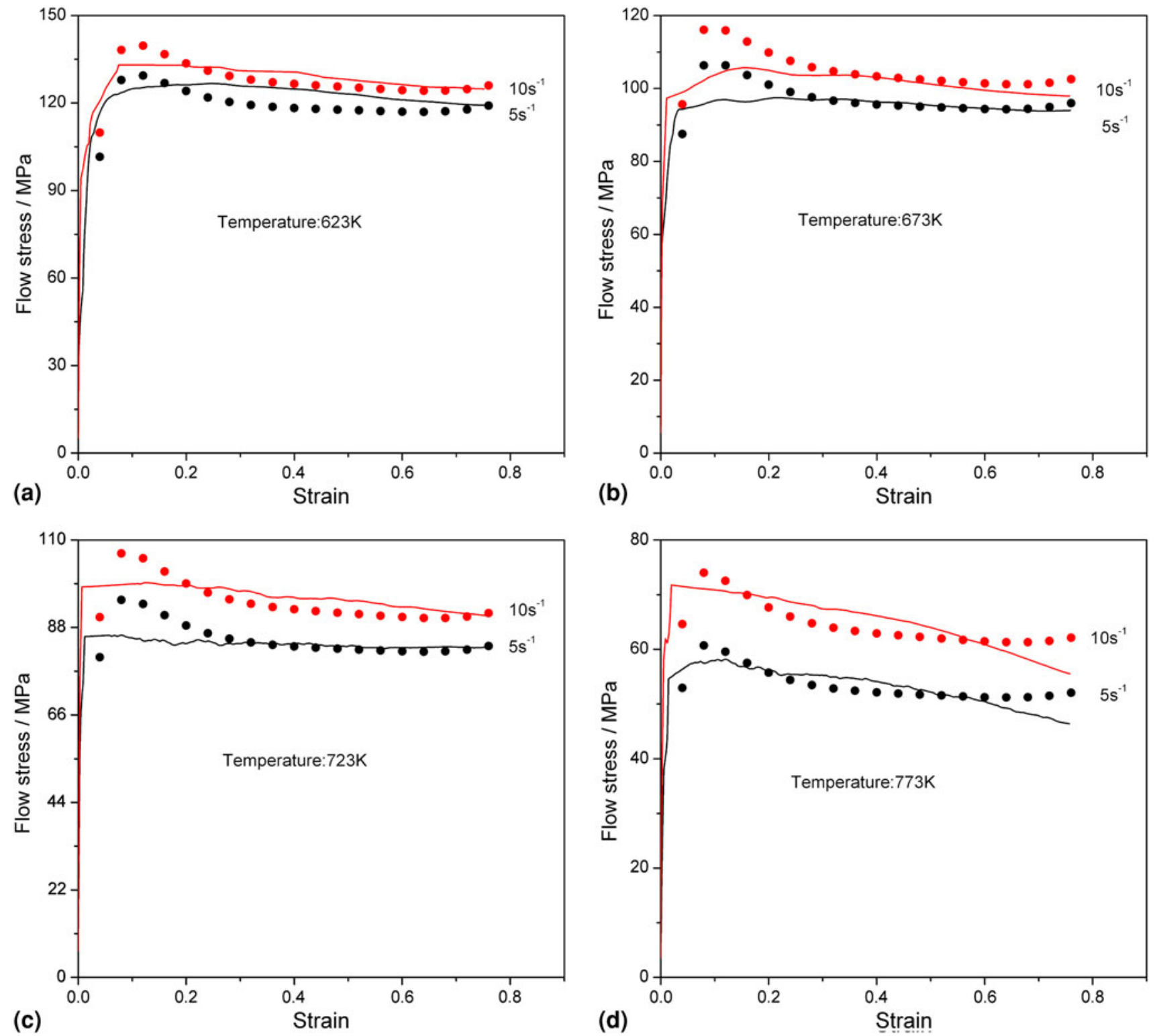

Fig. 16 The comparison of the experimental data and the predicted data at (a) $T=623 \mathrm{~K}$, (b) $T=673 \mathrm{~K}$, (c) $T=723 \mathrm{~K}$, and (d) $T=773 \mathrm{~K}$. The line represents the experimental data; the scatter plot represents the predicted data

the total number of the selected flow stress data points in the current study. The $R$ and AARE in this model are 0.98 and $7.8 \%$, respectively.

\section{Discussion}

In Fig. 12, it was observed that the data from the theoretic calculations coincide well with those of tests at the strain rate of $0.001,0.01$, and $0.1 \mathrm{~s}^{-1}$, but at strain rates of 5 and $10 \mathrm{~s}^{-1}$, the predicted data were not ideal. To get better agree with the experimental data, some adjustments based on the strain rate should be made. In Fig. 3, it is clear that the changes in trend vary with the strain rate, so the constitutive relationship should be discussed by dividing into two parts according to the strain rate, with one for strain rates of $0.001,0.01,0.1$, and $1 \mathrm{~s}^{-1}$ and the other for strain rates of 5 and $10 \mathrm{~s}^{-1}$. In Fig. 12, it could be observed that the predicted data have greatly changed with the strain, so that when adjusting the constitutive mode, only the relationship between flow stress and strain has been changed.

\subsection{Constitutive Relationship at the Strain Rates of 0.001, $0.01,0.1$, and $1 \mathrm{~s}^{-1}$}

Using the same method with Eq 13, the scatter plot which is shown in Fig. 13 could be obtained and a third-order polynomial is found to fit the variation trend of the scatter plot with a better correlation and generalization. The fourth-order polynomial function of $f_{\varepsilon}-\varepsilon$ is expressed as

$f_{\varepsilon}=44.23139+20.78854 \varepsilon-33.80465 \varepsilon^{2}+22.7331 \varepsilon^{3}$.

Through the MR test using SpSS, the result is shown in Table 9. The correction coefficient $A$ and the contribution 
weight $a, b, c, d, e$, and $f$ are shown in Table 10 . The values of $R$ and AARE in this model are 0.9865 and $6.0 \%$, respectively. The predicted flow stress from the strain-adjusted constitutive model is shown in Fig. 14.

\subsection{Constitutive Relationship at the Strain Rates of 5 and $10 s^{-1}$}

Applying the same method with Eq 10, a scatter plot could be obtained, as shown in Fig. 15, and a fourth-order polynomial is employed to fit the variation trend in the scatter plot. The fourth-order polynomial function of $f_{\varepsilon}-\varepsilon$ is expressed as

$$
\begin{aligned}
f_{\varepsilon}= & 91.43945+64.6556 \varepsilon-266.00547 \varepsilon^{2}+378.65081 \varepsilon^{3} \\
& -193.2289 \varepsilon^{4} .
\end{aligned}
$$

Through the MR test using SpSS, the result is shown in Table 11. The correction coefficient $A$ and the contribution weight $a, b, c, d, e$, and $f$ are shown in Table 12 . The values of $R$ and AARE in this model are 0.9860 and $3.0 \%$, respectively. The predicted flow stress from the strain-adjusted constitutive model is shown in Fig. 16.

Through the observation of Fig. 13 and 15, it is found that the data for theoretic calculations coincide well with those of tests at all strain rates.

\section{Conclusions}

Isothermal compression tests were employed on a Gleeble3500 thermo-mechanical simulator to investigate the hot deformation behavior of $\mathrm{SiC}_{\mathrm{p}} / \mathrm{Al}$ composites in the temperature range of $623-773 \mathrm{~K}$ and strain range of $0.001-10 \mathrm{~s}^{-1}$. The following conclusions were drawn:

(1) A modified constitutive equation based on DMNR was proposed to take into account not only the independent factors of processing parameters but also the interaction factors between them.

(2) The DMNR was based on the test data scatter plot that did not need a specific constitutive form in advance.

(3) Based on the change in the strain rate, the accuracy of the model has been changed. In Fig. 3, the softening mechanism of $\mathrm{SiC}_{\mathrm{p}} / \mathrm{Al}$ composites changed with the strain rate, which changes from DRV to DRX with increasing strain rate.

(4) The softening behavior of $\mathrm{SiC}_{\mathrm{p}} / \mathrm{Al}$ composites has changed with the strain rate, so the separate constitutive model acquired based on the strain rate is more accurate than the monolithic constitutive model.

\section{Acknowledgments}

The authors would like to express their sincere thanks for the research grants supported by the National Natural Science Foundation of China (Grant No. 51275414) and the Aeronautical Science Foundation of China (Grant No. 2011ZE53059).

\section{Open Access}

This article is distributed under the terms of the Creative Commons Attribution License which permits any use, distribution, and reproduction in any medium, provided the original author(s) and the source are credited.

\section{References}

1. T.S. Srivatsan, T.S. Sudarshan, and E.J. Lavernia, Processing of Discontinuously Reinforced Metal Matrix Composites by Rapid Solidification, Process Mater. Sci., 1995, 39, p 317-409

2. J. Hemanth, Quartz $\left(\mathrm{SiO}_{2}\right)$ Reinforced Chilled Metal Matrix Composite (CMMC) for Automotive Applications, Mater. Des., 2009, 30, p $323-$ 329

3. D.B. Miracle, Metal Matrix Composites-From Science to Technological Significance, Compos. Sci. Technol., 2005, 65, p 2526-2540

4. S. Basavarajappa and G. Chandramohan, Application of Taguchi Techniques to Study Dry Sliding Wear Behaviour of Metal Matrix Composites, Mater. Des., 2007, 28, p 1393-1398

5. T.W. Chou and A. Kelly, Fibre-Reinforced Metal-Matrix Composites, Composites, 1985, 16, p 187-206

6. C. Yan, Aerospace Applications of Silicon Carbide Particulate Reinforced Aluminum Matrix Composites, J. Mater. Eng., 2002, 6, p 3-6

7. J. Ma, D. Fu, and J. Wu, Physics and Chemistry Properties Engineering of Metal-Based Composites, Spacecr. Recover. Remote Sens., 1999, 20, p 46-50

8. L. Yu, X. Mao, Y. Zhao et al., Advanced Progress on Research of Particulate Reinforced Titanium Composites, Rare Met. Lett., 2006, 25, p $1-5$

9. S.A. Khadem, S. Nategh, and H. Yoozbashizadeh, Structural and Morphological Evaluation of Al-5 vol.\%SiC Nanocomposite Powder Produced by Mechanical Milling, J. Alloys Compd., 2011, 509, p 2221-2226

10. S. Tzamtzis, N.S. Barekar, N.H. Babu, J. Patel, B.K. Dhindaw, and Z. Fan, Processing of Advanced $\mathrm{Al} / \mathrm{SiC}$ Particulate Metal Matrix Composites Under Intensive Shearing-A Novel Rheo-Process, Compos. A, 2009, 40, p 144-151

11. P. Zhang, F. Li, and H. Li, Optimization of General Constitutive Equation for Hot Deformation of SiC Particle Reinforced Al Matrix Composites, J. Aeronaut. Mater., 2009, 29, p 51-56

12. N.P. Cheng, S.M. Zeng, and Z.Y. Liu, Preparation, Microstructures and Deformation Behavior of SiCP/6066Al Composites Produced by PM Route, J. Mater. Process. Technol., 2008, 202, p 27-40

13. N. Bontcheva and G. Petzov, Microstructure Evolution During Metal Forming Processes, Comput. Mater. Sci., 2003, 28, p 563-573

14. N. Bontcheva, G. Petzov, and L. Parashkevova, Thermomechanical Modelling of Hot Extrusion of Al-Alloys, Followed by Cooling on the Press, Comput. Mater. Sci., 2006, 38, p 83-89

15. H. Grass, C. Krempaszky, and E. Werner, 3-D FEM-Simulation of Hot Forming Processes for the Production of a Connecting Rod, Comput. Mater. Sci., 2006, 36, p 480-489

16. X. He, Z. Yu, and X. Lai, A Method to Predict Flow Stress Considering Dynamic Recrystallization During Hot Deformation, Comput. Mater. Sci., 2008, 44, p 760-764

17. Y.C. Lin, M.S. Chen, and J. Zhang, Modeling of Flow Stress of 42CrMo Steel Under Hot Compression, Mater. Sci. Eng. A, 2009, 499, p $88-92$

18. Y.C. Lin and G. Liu, A New Mathematical Model for Predicting Flow Stress of Typical High-Strength Alloy Steel at Elevated High Temperature, Comput. Mater. Sci., 2010, 48, p 54-58

19. T. Seshacharyulu, S. Medeiros, W. Frazier, and Y. Prasad, Hot Working of Commercial Ti-6Al-4V with an Equiaxed $\alpha-\beta$ Microstructure: Materials Modeling Considerations, Mater. Sci. Eng. A, 2000, 284, p 184-194

20. H. McQueen, Development of Dynamic Recrystallization Theory, Mater. Sci. Eng. A, 2004, 387, p 203-208

21. K. Ohwue, T. Yoshida, and M. Usuda, Influence of Material Properties and Work Process Factors in Sheet Metal Forming, Proceedings of the 4th International Conference on Numerical Methods in Industrial Forming Processes-Numisheet, Vol. 92, 1992, p 521-525 
22. R.H. Wagoner, Y.H. Kim, and Y.T. Keum, 3-D Sheet Forming Analysis Including the Effects of Strain-Hardening, Rate-Sensitivity, Anisotropy, Friction, Heat Generation and Transfer, Adv. Technol. Plast., 1990, 4, p 1751-1756

23. G.R. Johnson and W.H. Cook, A Constitutive Model and Data for Metals Subjected to Large Strains, High Strain Rates and High Temperatures, Proceedings of Seventh International Symposium on Ballistics, The Hague, 1983, p 541-547

24. F.J. Zerilli and R.W. Armstrong, Dislocation Mechanics Based Constitutive Relations for Material Dynamics Calculations, J. Appl. Phys., 1987, 61(5), p 1816-1825

25. D. Samantaray, S. Mandal, and A.K. Bhaduri, A Comparative Study on Johnson Cook, Modified Zerilli-Armstrong and Arrhenius-Type Constitutive Models to Predict Elevated Temperature Flow Behaviour in Modified 9Cr-1Mo Steel, Comput. Mater. Sci., 2009, 47, p 568576

26. S.-T. Chiou, W.-C. Cheng, and W.-S. Lee, Strain Rate Effects on the Mechanical Properties of a Fe-Mn-Al Alloy Under Dynamic Impact Deformations, Mater. Sci. Eng. A, 2005, 392, p 156-162

27. W.-S. Lee and C.-Y. Liu, Comparison of Dynamic Compressive Flow Behavior of Mild and Medium Steels over Wide Temperature Range, Metall. Mater. Trans. A, 2005, 36, p 3175-3185

28. W.-S. Lee and C.-Y. Liu, The Effects of Temperature and Strain Rate on the Dynamic Flow Behaviour of Different Steels, Mater. Sci. Eng. $A, 2006,426$, p 101-113

29. G.R. Johnson and T.J. Holmquist, Evaluation of Cylinder-Impact Test Data for Constitutive Model Constants, J. Appl. Phys., 1988, 64, p 3901-3910

30. G.Z. Voyiadjis and F.H. Abed, Microstructural Based Models for bcc and fcc Metals with Temperature and Strain Rate Dependency, Mech. Mater., 2005, 37, p 355-378
31. S. Dey, T. Børvik, O.S. Hopperstad, and M. Langseth, On the Influence of Constitutive Relation in Projectile Impact of Steel Plates, Int. J. Impact Eng., 2007, 34, p 464-486

32. A.M. Lennon and K.T. Ramesh, The Influence of Crystal Structure on the Dynamic Behavior of Materials at High Temperatures, Int. J. Plast., 2004, 20, p 269-290

33. O. Sabokpa, A. Zarei-Hanzaki, H.R. Abedi, and N. Haghdadi, Artificial Neural Network Modeling to Predict the High Temperature Flow Behavior of an AZ81 Magnesium Alloy, Mater. Des., 2012, 39, p 390 396

34. D. Samantaray, S. Mandal, A. Bhaduri, S. Venugopal, and P. Sivaprasad, Analysis and Mathematical Modelling of Elevated Temperature Flow Behaviour of Austenitic Stainless Steels, Mater. Sci. Eng. A, 2011, 528, p 1937-1943

35. M. Xiao, F. Li, W. Zhao, and G. Yang, Constitutive Equation for Elevated Temperature Flow Behavior of TiNiNb Alloy Based on Orthogonal Analysis, Mater. Des., 2012, 35, p 184-193

36. B. Wu, M.Q. Li, and D.W. Ma, The Flow Behavior and Constitutive Equations in Isothermal Compression of 7050 Aluminum Alloy, Mater. Sci. Eng. A, 2012, 542, p 79-87

37. E.C. Aifantis, The Physics of Plastic Deformation, Int. J. Plast., 1987, 3, p 211-247

38. S. Bodner and Y. Partom, Constitutive Equations for Elastic-Viscoplastic Strain-Hardening Materials, J. Appl. Mech., 1975, 42, p 385

39. P. Perzyna, The Constitutive Equations for Rate Sensitive Plastic Materials, Q. Appl. Math., 1963, 20, p 321-332

40. C. Sellars and W. Tegart, Hot Workability, Int. Metall. Rev., 1972, 17, p $1-24$

41. S. Srinivasulu and A. Jain, A Comparative Analysis of Training Methods for Artificial Neural Network Rainfall-Runoff Models, Appl. Soft Comput., 2006, 6, p 295-306 